\title{
Reversible Disruption of Neuronal Mitochondria by Ischemic and Traumatic Injury Revealed by Quantitative Two-Photon Imaging in the Neocortex of Anesthetized Mice
}

\author{
(10Mikhail Kislin, ${ }^{1}$ - Jeremy Sword, ${ }^{2}$ Ioulia V. Fomitcheva, ${ }^{5}$ Deborah Croom, ${ }^{2}$ Evgeny Pryazhnikov,,${ }^{1,3}$ Eero Lihavainen, ${ }^{4}$ \\ Dmytro Toptunov, ${ }^{3}{ }^{\circledR}$ Heikki Rauvala, ${ }^{1}$-Andre S. Ribeiro, ${ }^{4}$ Leonard Khiroug, ${ }^{1,3}$ and ${ }^{\circledR S e r g e i}$ A. Kirov ${ }^{2,5}$ \\ ${ }^{1}$ Neuroscience Center, University of Helsinki, Helsinki, Finland FI-00014, ${ }^{3}$ Neurotar Ltd, Helsinki, Finland FI-00790, ${ }^{4}$ Laboratory of Biosystem Dynamics, \\ Department of Signal Processing, Tampere University of Technology, Tampere, Finland FI-33101, and ${ }^{2}$ Brain and Behavior Discovery Institute and \\ ${ }^{5}$ Department of Neurosurgery, Medical College of Georgia at Augusta University, Augusta, Georgia 30912
}

Mitochondria play a variety of functional roles in cortical neurons, from metabolic support and neuroprotection to the release of cytokines that trigger apoptosis. In dendrites, mitochondrial structure is closely linked to their function, and fragmentation (fission) of the normally elongated mitochondria indicates loss of their function under pathological conditions, such as stroke and brain trauma. Using in vivo two-photon microscopy in mouse brain, we quantified mitochondrial fragmentation in a full spectrum of cortical injuries, ranging from severe to mild. Severe global ischemic injury was induced by bilateral common carotid artery occlusion, whereas severe focal stroke injury was induced by Rose Bengal photosensitization. The moderate and mild traumatic injury was inflicted by focal laser lesion and by mild photo-damage, respectively. Dendritic and mitochondrial structural changes were tracked longitudinally using transgenic mice expressing fluorescent proteins localized either in cytosol or in mitochondrial matrix. In response to severe injury, mitochondrial fragmentation developed in parallel with dendritic damage signified by dendritic beading. Reconstruction from serial section electron microscopy confirmed mitochondrial fragmentation. Unlike dendritic beading, fragmentation spread beyond the injury core in focal stroke and focal laser lesion models. In moderate and mild injury, mitochondrial fragmentation was reversible with full recovery of structural integrity after 1-2 weeks. The transient fragmentation observed in the mild photo-damage model was associated with changes in dendritic spine density without any signs of dendritic damage. Our findings indicate that alterations in neuronal mitochondria structure are very sensitive to the tissue damage and can be reversible in ischemic and traumatic injuries.

Key words: brain trauma; dendrite; mitochondria; stroke; structural dynamics; two-photon in vivo imaging

\section{Significance Statement}

During ischemic stroke or brain trauma, mitochondria can either protect neurons by supplying ATP and adsorbing excessive $\mathrm{Ca}^{2+}$, or kill neurons by releasing proapoptotic factors. Mitochondrial function is tightly linked to their morphology: healthy mitochondria are thin and long; dysfunctional mitochondria are thick (swollen) and short (fragmented). To date, fragmentation of mitochondria was studied either in dissociated cultured neurons or in brain slices, but not in the intact living brain. Using real-time in vivo two-photon microscopy, we quantified mitochondrial fragmentation during acute pathological conditions that mimic severe, moderate, and mild brain injury. We demonstrated that alterations in neuronal mitochondria structural integrity can be reversible in traumatic and ischemic injuries, highlighting mitochondria as a potential target for therapeutic interventions.

\section{Introduction}

In addition to supplying cellular energy, neuronal mitochondria are involved in the biosynthesis of neurotransmitters and the

Received May 5, 2016; revised 0ct. 3, 2016; accepted 0ct. 23, 2016.

Author contributions: M.K., H.R., A.S.R., L.K., and S.A.K. designed research; M.K., J.S., I.V.F., D.C., E.P., E.L., and D.T. performed research; M.K., J.S., I.V.F., D.C., E.P., E.L., and D.T. analyzed data; M.K., L.K., and S.A.K. wrote the paper.

This work was supported by the Academy of Finland Grant SA-126321, FGSN, CIMO, and University of Helsinki to L.K., Emil Aaltonen Foundation to E.L., Academy of Finland Grants 295027 and 305342, and Jane and Aatos Erkko Foundation Grant 610536 to A.S.R., and by National Institutes of Health Grant NS 083858 to S.A.K. We thank Libby Perry and Brendan Marshall (Electron Microscopy Core at the Medical College of Georgia) for assistance with electron microscopy; and Julia Kolikova (Neurotar Ltd) and Marina Tibeykina (In Vivo Microscopy Unit at the University of Helsinki) for assistance with animal surgeries. regulation of intracellular $\mathrm{Ca}^{2+}$ signaling, acting as a "sink" and "store" of $\mathrm{Ca}^{2+}$, and thereby are important for synaptic communication and neuronal plasticity (Chan, 2006; Mattson et al.,
E.P. and D.T. are part-time employees of Neurotar Ltd. L.K. is a co-owner of Neurotar Ltd. The remaining authors declare no competing financial interests.

Correspondence should be addressed to either of the following: Dr. Leonard Khiroug, In Vivo Microscopy Unit, Neuroscience Center, PO Box 56 (Viikinkaari 4), University of Helsinki, Fl-00014, Helsinki, Finland, E-mail: leonard.khirug@helsinki.fi; or Sergei A. Kirov, Multiphoton Imaging Laboratory, Department of Neurosurgery and Brain and Behavior Discovery Institute, Medical College of Georgia at Augusta University, 112015 th Street, CB-3706, Augusta, GA 30912-2630, E-mail: skirov13@gmail.com.

DOI:10.1523/JNEUROSCI.1510-16.2016

Copyright $\odot 2017$ the authors $\quad 0270-6474 / 17 / 370333-16 \$ 15.00 / 0$ 
2008). Traumatic and ischemic brain injuries are multifactorial disorders that lead to a spectrum of pathological changes, having a significant influence on the patients' health status. Although the primary impact differs, the mechanisms of injury progression can be similar to some extent (Kunz et al., 2010; Dirnagl, 2012). Interruption of blood flow eliminates the supply of oxygen and glucose and prevents the brain from generating ATP. Ion and water imbalances have long been considered as chief contributors to acute, irreversible brain injury together with a complex sequence of pathological events, including spreading depolarizations (SDs), excitotoxicity, calcium overload, generation of reactive oxygen species, and activation of cell death pathways (Lee et al., 1999; Hossmann, 2006; Hartings et al., 2016). All of these conditions involve mitochondria participation at some level.

Previously, the role of mitochondrial dysfunction has been addressed in vivo using endpoint measures of histological and biochemical markers (Matsumoto et al., 1999; Schinzel et al., 2005) or classic ultrastructural studies (Garcia et al., 1978; Solenski et al., 2002). Employment of in vitro preparations, such as primary cultured neurons, acute and organotypic brain slices have provided a mechanistic concept of mitochondria alteration during traumatic and ischemic injury-like events. Spreading depolarizations (Hartings et al., 2016), glutamate excitotoxicity (Rintoul et al., 2003; Abramov and Duchen, 2008; Brustovetsky et al., 2009), and/or ionic-oxidative stress lead to mitochondrial $\mathrm{Ca}^{2+}$ overload. This triggers the mitochondrial membrane potential collapse, generation of excessive reactive oxygen species, cessation of oxidative phosphorylation, and the opening of the mitochondrial permeability transition pore, which results in the eventual outer membrane rupture with release of cytochrome $c$ and other apoptogenic proteins (Halestrap, 2006).

Many lines of evidence obtained in vitro suggest that mitochondrial functions are directly related to their morphology. Abnormal mitochondrial dynamics and fragmentation of the mitochondrial network into small spherical structures are considered hallmarks of mitochondrial injury (Rugarli and Langer, 2012; Kremneva et al., 2013; Otera et al., 2013). Such collapse of the mitochondrial network may be the result of either membrane permeability transition or disruption of mitochondria dynamics induced by traumatic or ischemic conditions. However, the relevance of these in vitro observations for in vivo conditions remains largely unknown.

Recent advances in optical techniques, such as two-photon laser scanning microscopy (Svoboda et al., 1997; Peron et al., 2015) and genetic animal models (Feng et al., 2000; Misgeld et al., 2007), allow repetitive real-time visualization of subcellular structures. Previously, we have developed an automatic approach, based on supervised statistical computer learning, for quantifying the degree of mitochondrial fragmentation in cortical neurons, and validated it using the irreversible global ischemia paradigm (Lihavainen et al., 2015). Here, we took advantage of this automatic analysis algorithm and performed a longitudinal in vivo two-photon imaging study of the neuronal mitochondrial fragmentation and recovery in response to mild, moderate, and severe injury using several animal models of acute neurological disorders.

\section{Materials and Methods}

\section{Animals and surgical procedures}

We used male and female adult mice ranging from 2 to 5 months. In total, 73 mice were used: 37 Thyl-mitoCFP mice (B6.Cg-Tg(Thy1-CFP/ COX8A)C1Lich/J; RRID:IMSR_JAX:007940) (Misgeld et al., 2007), 10
Thy1-YFP(H) mice (B6.Cg-Tg(Thy1-YFP)HJrs/J; RRID:IMSR_JAX: 003782), 6 Thy1-GFP(M) mice (B6.Cg-Tg(Thy1-EGFP)MJrc/J; RRID: IMSR_JAX:007919) (Feng et al., 2000), 5 dual Thy1-GFP(M) $\times$ Thy1mitoCFP mice, and 15 C57BL/6J mice. The mice were bred and kept in group cages in the certified animal facilities of the University of Helsinki and Medical College of Georgia and provided with food and water ad libitum. Local authority (ELÄINKOELAUTAKUNTA-ELLA) approved the animal license (ESAVI/2857/04.10.03/2012) that included all procedures conducted at the University of Helsinki. All procedures conducted at Medical College of Georgia followed National Institutes of Health guidelines for the humane care and use of laboratory animals and underwent yearly review by the Animal Care and Use Committee at the Medical College of Georgia. Mice were allowed free access to room air and were anesthetized with intraperitoneal injection of mixture of ketamine ( $80 \mathrm{mg} / \mathrm{kg}$ body weight) and xylazine $(10 \mathrm{mg} / \mathrm{kg})$ during surgery and all longitudinal imaging experiments. In six terminal imaging experiments followed by transcardiac perfusion for tissue collection for electron microscopy (EM), mice were anesthetized with an intraperitoneal injection of urethane $(1.5 \mathrm{mg} / \mathrm{g})$. In these mice, the trachea was cannulated, and animals were ventilated mechanically with an SAR-830 ventilator (CWE). The depth of anesthesia, blood oxygen saturation level (>90\%), and heart rate ( $450-650$ beats/ $\mathrm{min}$ ) were monitored continuously with a MouseOx pulse oximeter (STARR Life Sciences) equipped with a mouse thigh sensor. A heating pad was used to maintain the core temperature of $37^{\circ} \mathrm{C}$. Implantation of cranial window was performed as described previously (Holtmaat et al., 2009; Risher et al., 2010). Briefly, a subcutaneous injection of $0.1 \%$ lidocaine was administered to reduce local pain at the incision site, and then skin and connective tissue attached to the skull were removed. To form an $\sim 3 \times 3 \mathrm{~mm}$ round cranial window, cranial bone over the somatosensory cortex was carefully removed. The brain was then covered with sterile cortex buffer containing the following (in $\mathrm{mm}$ ): $125 \mathrm{NaCl}, 5 \mathrm{KCl}, 10$ glucose, $10 \mathrm{HEPES}, 2 \mathrm{CaCl}_{2}$, and $2 \mathrm{MgSO}_{4}, \mathrm{pH}$ 7.3, and a 5-mm-diameter \#1.5 glass coverslip (Electron Microscopy Sciences) was placed over the window and sealed with a custom-made metal holder using dental cement. Mice recovered for 21-40 d before two-photon imaging. In 6 mice used for terminal imaging experiments followed by EM studies, an optical chamber was constructed by covering the intact dura with a thin layer of $1.5 \%$ agarose prepared in a cortex buffer. The chamber was left open to facilitate access with a glass recording microelectrode. The $\mathrm{Ag} / \mathrm{AgCl}$ pellet ground electrode (A-M Systems) was installed under the skin above the nasal bone.

\section{In vivo two-photon microscopy imaging of blood flow and} neuronal mitochondria

Mice were imaged with a FV1000MPE two-photon microscope (Olympus) using the $25 \times / 1.05 \mathrm{NA}$ (numerical aperture) water-immersion objective. To achieve stable imaging and precise repositioning between imaging sessions, mice were placed under the microscope by attaching the metal holder to the custom-built frame fixed to the motorized stage (Prior Scientific). Fluorescence was excited with Mai Tai DeepSee titanium:sapphire femtosecond laser (SpectraPhysics) tuned to $860 \mathrm{~nm}$. As measured by using the FWHM of a point spread function obtained with subresolution beads, the microscope has the resolution of $0.332 \mu \mathrm{m}$ in the lateral dimension and $1.640 \mu \mathrm{m}$ in the axial dimension. Emission light was collected by PMT detectors with a pinhole entirely opened using the following bandpass filters: $420-500,515-560$, and $590-650 \mathrm{~nm}$. The laser power at the objective front focal plane $(0.05-0.40 \mu \mathrm{J})$ required for image acquisition was adjusted to the lowest possible level for each animal. Three-dimensional (3D) images were taken at $0.5-1 \mu \mathrm{m}$ increments across a large scale $500 \times 500 \mu \mathrm{m}$ imaging field, yielding a nominal spatial resolution of 2.05 pixels $/ \mu \mathrm{m}$ ( $12 \mathrm{bits} / \mathrm{pixel}, 2 \mu \mathrm{s}$ pixel time) or across $169 \times 169 \mu \mathrm{m}$ field (6.06 pixels $/ \mu \mathrm{m}, 12 \mathrm{bits} /$ pixel, $2 \mu$ s pixel time $)$ for higher resolution. A $0.1 \mathrm{ml}$ bolus of $5 \%$ (w/v) $70 \mathrm{kDa}$ dextran conjugated with Texas Red was injected into the tail vein, and blood flow was imaged in a repetitive line scan mode (at a rate of $1.5 \mathrm{kHz}$ for $30 \mathrm{~s}$ ) along the central axis of surface arterioles and venules. Moving red blood cells (RBCs) produce dark bands with a slope on the resulting space-time images (Kleinfeld et al., 1998). The slope was used to determine RBC velocity and flow direction. 


\section{Cortical injuries}

Four different injury types, ranging from severe to mild, were inflicted in anesthetized mice, and the same volume of affected cortex was imaged before and after injury at several time points. At least two control volumes were selected at the distances between 0.5 and $2.0 \mathrm{~mm}$ away from the injury site. They were imaged before and after injury at several time points. To compare changes in mitochondrial morphology associated with each injury type, image sessions were performed during the acute $(0-3 \mathrm{~h})$, subchronic $(2,4$, and $7 \mathrm{~d})$, and chronic (2-3 weeks) phases of injury.

Global ischemia model was used to cause severe brain injury, followed by short-term imaging for 1-2 $\mathrm{h}$. Transient global cerebral ischemia was induced by bilateral common carotid artery occlusion (BCCAO) during two-photon imaging (Murphy et al., 2008; Risher et al., 2012). Briefly, common carotid artery bifurcations were exposed after skin incision on the midline of the ventral neck and separated from the vagus nerves and connective tissue. One suture (3-0, polyester, Ethicon) was placed around each artery. For transient occlusion, sutures were tensioned on the microscope stage for $5 \mathrm{~min}(n=5$ mice $)$ or $8 \mathrm{~min}(n=7$ mice $)$ and then subsequently released for reperfusion.

Photothrombotic stroke model was used to cause severe focal brain injury that can be followed by longitudinal imaging for several weeks. Rose Bengal photosensitization (RBPS) was induced in the somatosensory cortex using the photothrombotic method (Watson et al., 1985; Labat-gest and Tomasi, 2013) of unilateral focal ischemic stroke with the following modification. Three or four large-scale $z$-stacks were acquired before RBPS. Then, a cortical region, $720 \mu \mathrm{m}$ in diameter, near cranial window border was illuminated with a green epifluorescent light (535 \pm $25 \mathrm{~nm}$ ) through a $25 \times / 1.05 \mathrm{NA}$ objective (the average power through the objective was 3-10 mW) after the tail vein injection of the Rose Bengal solution $(10 \mathrm{mg} / \mathrm{kg}$, in PBS). Typically, photosensitization was performed for 1-5 min until clot formation was confirmed visually in the majority of the vessels. RBC velocity and blood flow direction were measured 20 min before RBPS and then every $30 \mathrm{~min}$ for $3 \mathrm{~h}$. Ischemic core and remote areas were identified by these measurements.

A moderate brain injury was achieved with the focal laser lesion (FLL). FLL was applied at the depth of $80-110 \mu \mathrm{m}$ from dura mater by targeting a spherical region of $50 \mu \mathrm{m}$ in diameter with the laser beam and irradiating it for $0.42 \pm 0.16 \mathrm{~s}$ with the $1.98 \mathrm{~W}$ of infrared laser energy at 800 $\mathrm{nm}$, resulting in 5-20 $\mu \mathrm{J}$ at the objective focal plane. To minimize bleeding, the FLL region was selected far away from large vessels. The FLL injury typically was confined to a roughly spherical area with a $60-530 \mathrm{pl}$ volume surrounding the laser targeted region (as indicated by the immediate loss of CFP or YFP fluorescence and disruption of capillary network), which was surrounded by a perilesion site of $40-60 \mu \mathrm{m}$.

A mild photo-damage (MPD) was used to inflict a mild brain injury. MDP was achieved by zooming in with the factor of $3 \times$ to the center of a large scale image, resulting in $165 \times 165 \mu \mathrm{m}$ field and subsequent $z$-stack imaging of 100 optical sections with $1 \mu \mathrm{m}$ spacing and increased laser energy at the $860 \mathrm{~nm}$ laser wavelength, yielding $0.5-1 \mu \mathrm{J}$ in the objective focal plane the imaging field. The site and degree of injury were strictly controlled; thus, the response of mitochondrial morphology to the MPD was highly reproducible.

\section{Image processing and quantification}

Because the relatively poor $z$-axial resolution of two-photon microscopy hindered proper $3 \mathrm{D}$ object analyses, mitochondria were analyzed in individual optical sections. With this approach, we accurately measured the "projected length" of mitochondria in the 2D plane of the optical section. Segmentation of individual mitochondria within each optical section was completed with custom MATLAB-based scripts (The MathWorks) (Lihavainen et al., 2012). Briefly, images from $z$-stacks were passed to the Difference-of-Gaussians (DOG) filter that removed low-frequency fluctuations in intensity. Mitochondria binary masks were generated from the resulting image by thresholding the pixel values. To remove falsepositive objects and obtain better mitochondria size matching, a morphological erosion algorithm was applied. In addition, some connected components were discarded based on statistical properties associated with each locality computed from the original image. A set of morpho- logical features was extracted from high resolution mitochondria images using National Institutes of Health ImageJ software (RRID: SCR_003070) to represent their morphology and subtypes (tubule and globule) classified by MATLAB-based MicroP program (Peng et al., 2011).

The resolution and signal-to-noise ratio of the large scale images limit accurate segmentation of individual mitochondria. To overcome these limitations, we used our recently developed supervised-learning-based analysis algorithm (Lihavainen et al., 2015) that estimates the degree of fragmentation of neuronal mitochondrial populations in a large region. The fragmentation score represents a continuous variable ranging from completely intact (score $=0$ ) to completely fragmented mitochondria $($ score $=1)$. The method automatically extracts the texture and morphological features from an image patch $(50 \mu \mathrm{m}$ block to 101 pixels; see Fig. $2 A$ ), based on training of the classifier and regression model. For training, a set of images is visually examined and each patch is classified and scored. Then, the previously trained classifier detects the regions containing mitochondria, and the fragmentation score is obtained from the regression model. Here, we used the classifier and regression model trained earlier on the dataset from control Thy1-mitoCFP mice and mice exposed to cardiac arrest (Lihavainen et al., 2015).

Image stacks acquired from Thy1-YFP(H) and Thy1-MitoCFP $\times$ Thyl-EGFP(M) mice were preprocessed with ImageJ software. To analyze dendritic morphology in dual transgenic mice, CFP signal was subtracted from the GFP channel. All $z$-stacks were stabilized and aligned over time. To quantify structural changes in dendritic morphology after injury, the percentage of beaded dendrites was determined from maximal intensity projections, which were cropped into $25 \mu \mathrm{m}$ blocks. Each block was manually assigned as beaded or intact based on criteria reported previously (Murphy et al., 2008; Sword et al., 2013; Steffensen et al., 2015). Data were double-checked with automated MATLAB-based BlebQuant program (Chen et al., 2011).

Automatic segmentation with Otsu's thresholding was applied to convert each optical section of labeled dendritic tuft to a binary image and to identify pixels corresponding to either dendritic structure or to the background. Density of dendritic tufts was calculated as a sum of foreground pixels per micrometer of lesion or perilesional area. The same calculation was done to compute density of mitochondria from binary image segmented as described above for "projected length" measurement.

To assess spine density, the same dendritic segments $(20-45 \mu \mathrm{m})$ of the tuft that projected laterally were identified and cropped from $z$-stack at different time points. Obtained substacks were deconvolved in AutoQuant X3 (Media Cybernetics; RRID:SCR_002465). Dendritic spines were counted manually using 3D tools of NeuronStudio (Rodriguez et al., 2008), and spine density was calculated as the number of spines per micrometer of the dendritic segment length.

\section{Experimental procedures used to obtain samples for EM analysis}

Transient global cerebral ischemia was induced on the microscope stage by BCCAO as described above. The cortical slow DC potential and spontaneous EEG activity were recorded with a glass microelectrode (filled with $0.9 \% \mathrm{NaCl}, 1-2 \mathrm{M} \Omega$ ) inserted through the dura to the site of imaged dendrites within layer I of the somatosensory cortex. Signals were recorded with a MultiClamp 200B amplifier, filtered at $1 \mathrm{kHz}$, and digitized at $10 \mathrm{kHz}$ with a Digidata 1322A interface board (Molecular Devices). Ischemia was verified by laser speckle imaging, and the onset of dendritic beading was monitored with two-photon imaging.

\section{In vivo two-photon microscopy imaging of dendritic beading}

Images were collected with infrared-optimized $40 \times / 0.8 \mathrm{NA}$ waterimmersion objective (Carl Zeiss) using the Zeiss LSM 510 NLO META multiphoton system mounted on the motorized upright Axioscope 2FS microscope. The scan module was coupled directly with the SpectraPhysics titanium:sapphire broadband, mode-locked laser (Mai-Tai) tuned to $910 \mathrm{~nm}$ for two-photon excitation. The 3D time-lapse images were taken at $1 \mu \mathrm{m}$ increments (with $\sim 20$ sections per $z$-stack) across a $75 \times 75 \mu \mathrm{m}$ imaging field. After confirmation of the intact dendritic structure in sham-operated mice $(n=3)$ or dendritic beading after $\operatorname{BCCAO}(n=3)$, mice were perfusion-fixed through the heart at 180 
mmHg with mixed aldehydes (2\% PFA, 2.5\% glutaraldehyde, 2 mM $\mathrm{CaCl}_{2}, 4 \mathrm{~mm} \mathrm{MgSO}_{4}$, in $0.1 \mathrm{M}$ sodium cacodylate, $\mathrm{pH}$ 7.4), and brain was processed for EM.

\section{Electron microscopy and image analysis}

A small piece of tissue containing somatosensory cortex was microdissected from the coronal section of the brain and subsequently processed with standard microwave-enhanced procedures through osmium, uranyl acetate, dehydration with a graded ethanol series, and embedding in Epon-Araldite resin (Kirov et al., 1999). Thin sections at $150 \mu \mathrm{m}$ from the cortical surface were cut with a diamond knife on an EM UC6 ultramicrotome (Leica), collected on pioloform-coated copper Synaptek slot grids (Electron Microscopy Sciences), and stained with uranyl acetate and lead citrate. These protocols produced well-stained and readily identifiable neuronal processes (see Fig. 3D). Five to 13 fields were photographed randomly from each mouse (total 46 fields) at the JEOL 1230 transmission electron microscope (JEOL). Images were captured digitally at a magnification of $5000 \times$ using the UltraScan 4000 camera (Gatan). The images were randomized, coded, and analyzed blind as to condition. Each cross-sectioned dendrite containing cross-sectioned mitochondria was identified, and mitochondria cross-sectional area was measured with the freely available RECONSTRUCT software (Fiala, 2005) (RRID:SCR_002716). Each image provided $\sim 107 \mu \mathrm{m}^{2}$ to evaluate mitochondria swelling. For serial section transmission electron microscopy (ssTEM), samples were obtained at $150 \mu \mathrm{m}$ from the cortical surface from 2 sham-operated and 2 mice subjected to BCCAO. One series from each animal, containing 167-220 sections, each $\sim 53 \mathrm{~nm}$ thick, were cut and collected on pioloform-coated slot grids, and serial sections were photographed at $5000 \times$. The $3 \mathrm{D}$ alignment, surfaced reconstructions, and analyses were completed using RECONSTRUCT.

Laser speckle imaging. Two-dimensional (2D) maps of cerebral blood flow (CBF) with high spatiotemporal resolution were acquired by laser speckle imaging as described previously (Dunn et al., 2001; Sigler et al., 2008; Risher et al., 2010). Briefly, the cortical surface was illuminated through an anamorphic beam expander (Edmund Optics) by a $785 \mathrm{~nm}$ StockerYale laser (ProPhotonix) at an angle of $\sim 30^{\circ}$ and imaged with a $4 \times / 0.075$ NA objective (Zeiss). Real-time speckle imaging was used with custom written LabView software (National Instruments; RRID: SCR_014325) (Yang et al., 2011) and modified for use with the Pantera $1 \mathrm{M} 60$ camera (Dalsa) using the XCLIB DLL library (EPIX). Laser speckle contrast was obtained by dividing the SD image by the mean of each raw image with a $5 \times 5$ pixel sliding window for immediate display. Fifty frames were saved individually as 32 bit images in LabView and averaged offline using ImageJ to obtain a single image for figures.

\section{Statistics}

Origin software (OriginLab) was used for statistical analyses and to plot graphs. A two-tailed paired $t$ test and one-way ANOVA followed by Tukey's post hoc test were used to compare group means at different time points. One-sample and unpaired Student's $t$ test was applied for analyses of dendritic beading percentage. Kolmogorov-Smirnov test and MannWhitney rank sum test were used for statistical analysis of cross-sectional mitochondria area in EM. Changes in RBC velocity were expressed as percentage of baseline values. $\chi^{2}$ test was used to analyze mitochondria subgroups in two-photon and in EM images. The linear regression analysis was applied to quantify the strength of the relationship between two variables. The sample size of each experimental group is given in Results. All data analyses were performed blind to the experimental conditions. Data are presented as mean \pm SEM, except mitochondrial fragmentation score, which is given as median \pm SEM. The significance criterion was set at $p<0.05$.

\section{Results}

\section{Structure of cortical neuronal mitochondria in vivo}

We used in vivo two-photon microscopy and chronic cranial window preparation (Holtmaat et al., 2009; Paveliev et al., 2014) combined with Thy1-mitoCFP transgenic mouse strain (Misgeld et al., 2007) to study structure and distribution of mitochondria labeled with CFP fused to the mitochondria-targeted sequence from subunit VIII of human cytochrome $c$ oxidase. It was previously shown that this mitochondrial targeting sequence is sufficient for ubiquitous and exclusive expression of fusion proteins in the mitochondria of transgenic mice (Shitara et al., 2001; Chandrasekaran et al., 2006; Misgeld et al., 2007). Volume reconstruction of somatosensory cortex showed dense CFP labeling from cortical layer V and II/III pyramidal neurons (Fig. 1B). Such a high number of labeled cells did not allow distinguishing and tracing mitochondria in individual neurons, compared with sparse labeling of dendrites in Thy1-YFP(H) mice (Fig. 1C).

As visualized by mitoCFP in neocortex of adult mice, in vivo neuronal mitochondria appeared continuous, branched, and varicose with no abnormalities in morphology, such as fragmentation, vacuolization, or aggregation (Fig. 1D). Here, we selected mitochondria in molecular layer I and granular layer II/III and analyzed their morphology using the automated segmentation method (Lihavainen et al., 2012). Based on "projected length" of mitochondria segmentation in the 2D plane of the optical section, neuronal mitochondria were classified into globules and tubules using the automatic object subtyping method (Peng et al., 2011). Mitochondria highly varied in size (Fig. $1 E$ ) with most dendritic mitochondria having projected lengths of $<5 \mu \mathrm{m}$ (average $2.8 \pm 0.6 \mu \mathrm{m}$ ), whereas a small proportion of mitochondria were $>6 \mu \mathrm{m}$ long. Some mitochondria within cortical layer I were extremely long and formed large networks that extended well beyond $20 \mu \mathrm{m}$ (Popov et al., 2005). Average distribution of mitochondrial projected lengths calculated from 9 animals revealed that the projected length decreased significantly as a function of depth from the pia (Fig. 1E). The average projected length of mitochondria was $38.2 \pm 2.4 \%$ smaller at the depth of $180 \mu \mathrm{m}$ below cortical surface compared with that at the $50 \mu \mathrm{m}$ depth ( $p<0.001, n=9$ mice, $n=800$ mitochondria per mouse per depth). Similarly, the mitochondrial tubular-to-globular ratio changed significantly with depth $(p<0.01)$ (Fig. $1 G)$. Tubular mitochondria were predominant in superficial cortical layers, whereas globular mitochondria were observed more frequently in the granular layer II/III.

This observation may have at least two underlying reasons. First, the projected length of mitochondria may decrease with depth because the full length of mitochondria becomes smaller on average in deeper cortical layers. Second, projected length may decrease simply because the angle between the mitochondriabearing dendrites and the vertical axis becomes sharper with depth (Fig. 1C). Although we were not able to directly test the former hypothesis, we addressed the latter by analyzing the projected length of dendritic branches in the well-characterized Thy1-YFP(H) mice (Fig. $1 F, H$ ). Indeed, we observed very similar regularities in the dendrite projected lengths and in the depth dependence of object subtype ratios for the dendritic labeling as we did for mitochondrial labeling. Therefore, it is likely that the mitochondrial depth dependence in projected length and tubular-to-globular ratio are determined primarily by the angular position of dendritic tufts to the horizontal imaging plane. Thus, to minimize the bias, further mitochondrial analysis was conducted only in dendritic tufts within molecular layer I, where dendrites run almost parallel to the brain surface.

\section{Rapid, reperfusion-dependent mitochondrial fragmentation in the BCCAO model of global ischemia}

In the BCCAO model, abrupt reduction of blood flow results in a severe energy deficit and, in the absence of immediate reperfusion, leads to a permanent dendritic beading that marks irreversible neuronal injury (Murphy et al., 2008; Risher et al., 2012). In 
A

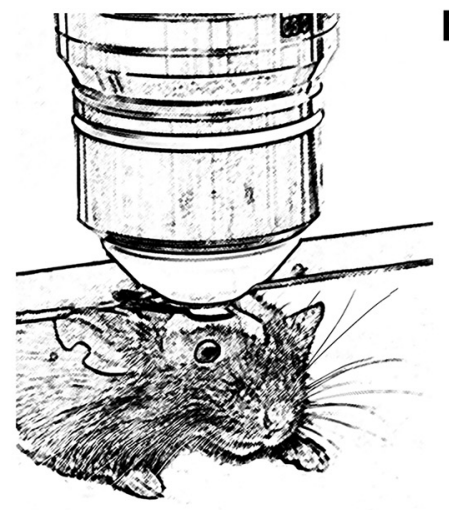

B

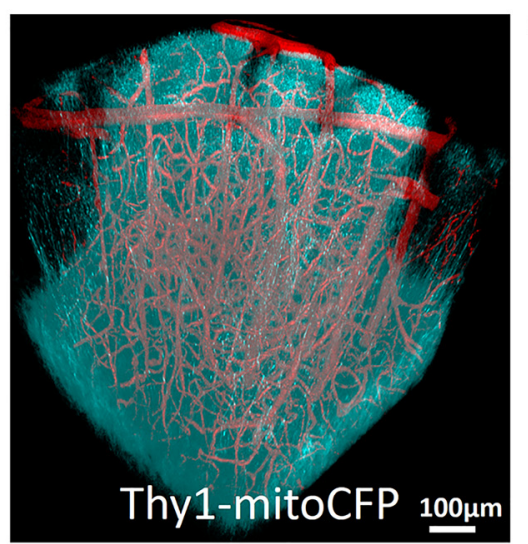

C

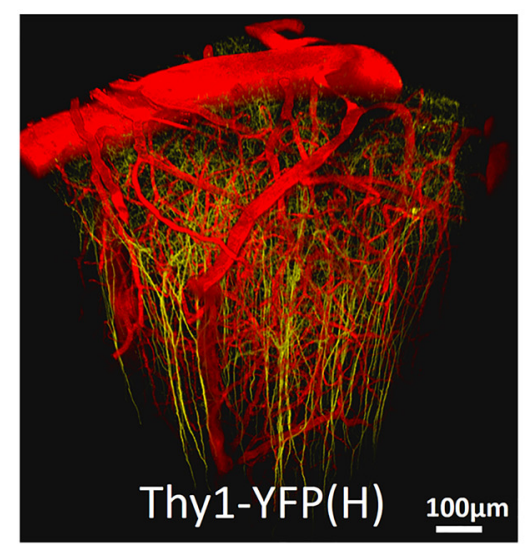

\section{D}
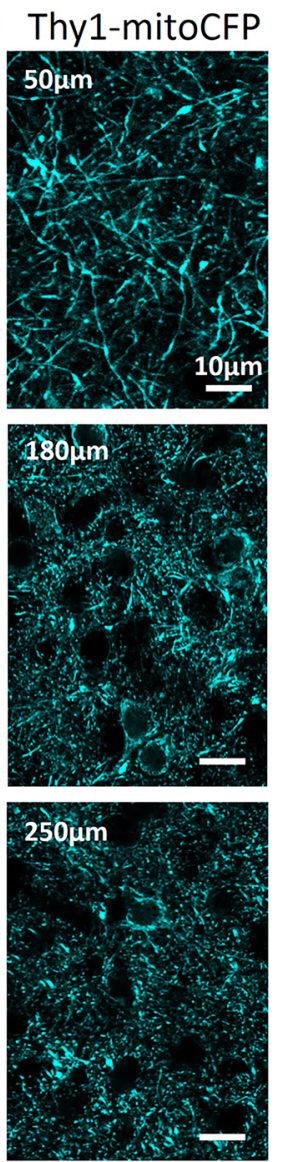
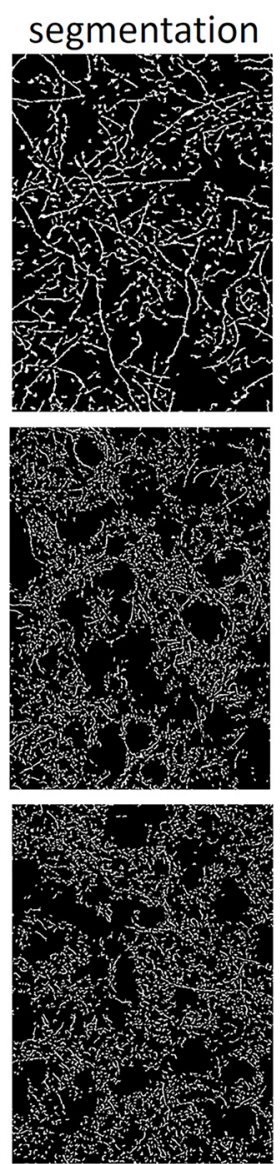
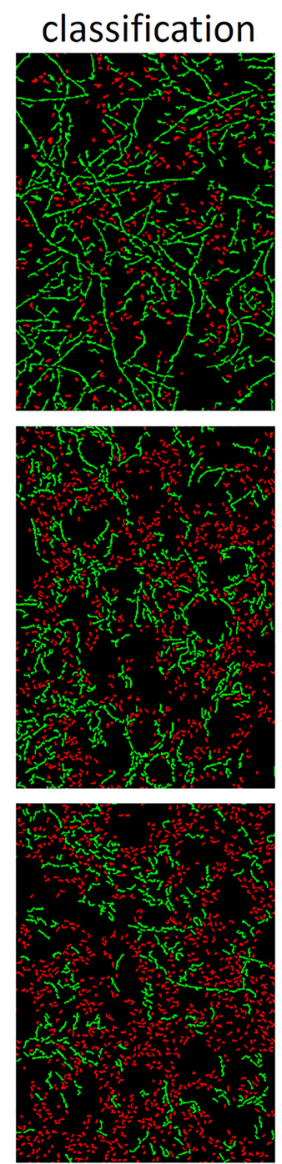

Mitochondrial CFP

E

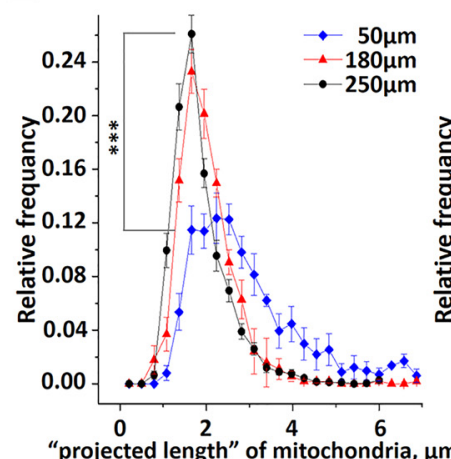

G

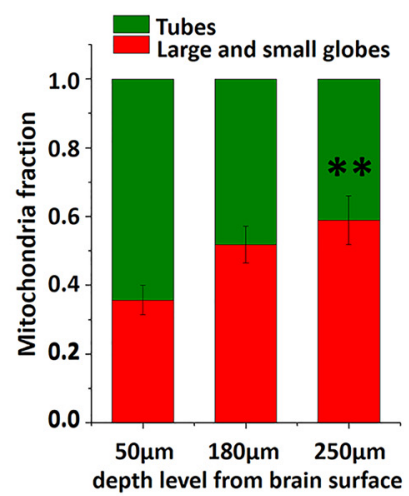

Cytosolic YFP

\section{$\mathbf{F}$}

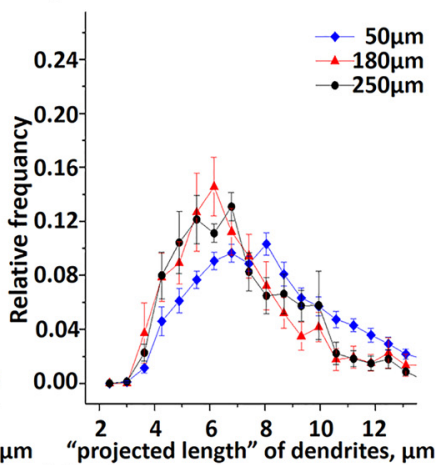

H

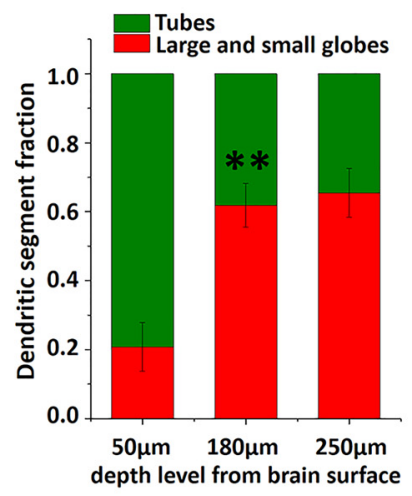

Figure 1. Intravital two-photon imaging of neuronal mitochondria. A, Schematic showing anesthetized mouse with chronically implanted cranial window attached to the custom-built frame under two-photon microscope. B, C, The 3D reconstruction of mitochondria and dendrites of pyramidal neurons and blood vessels in somatosensory cortex of the Thy1-mitoCFP and Thy1-YFP mice. CFP targeted to mitochondria (cyan pseudocolor) and cytosolic YFP (yellow pseudocolor) are expressed only in a fraction of cortical neurons. Although expression is driven by neuronal Thy1-promotor in both lines, more neurons are labeled by CFP than by YFP. Cortical vessels (red pseudocolor) are labeled with Texas Red dextran. D, Single two-photon images (left panels) from layers I and II/III of somatosensory cortex of Thy1-mitoCFP mice were segmented (central panels) and classified (right panels) into small and large globules (red) or tubules (green) mitochondria subtypes. $\boldsymbol{E}$, Average mitochondrial projected length distribution plotted at three different depth levels from the cortical surface. Asterisks indicate significant difference in the length between superficial and granular layers $\left(F_{(1,17)}=22.55\right.$, one-way ANOVA, ${ }^{* * *} p<0.001$, Tukey's post hoc test). $p<0.001$. $F$, Average distribution of dendritic tuft projected length calculated from single optical sections at three different depth levels from brain surface. $\mathbf{G}$, Percentage of tubular and globular mitochondria at different cortical depths. Asterisks indicate significant increase in the fraction of globular mitochondria at the granular layer II/III (**p $\left.<0.01, \chi_{(1,17)}^{2}=44.86\right)$. $\boldsymbol{H}$, Fraction of dendritic segments with projected globular length was higher in the deep cortical layers $\left({ }^{* *} p<0.01, \chi_{(1,9)}^{2}\right.$ $=18.86)$.

this respect, it resembles the ischemic core when compared with focal stroke. In our previous study, when global ischemia was induced by cardiac arrest (Lihavainen et al., 2015), the peak of neuronal mitochondrial fragmentation was observed within 5 min after heart failure. Therefore, it was desirable to select duration of occlusion that would result in severe but reversible fragmentation. In the preliminary set of experiments, 9 wild-type
C57BL mice were injected intravenously with the $70 \mathrm{kDa}$ Texas Red dextran and RBC velocity was monitored during BCCAO. Occlusion caused a sharp drop in RBC velocity to $6.4 \pm 4.7 \%$ of baseline toward the end of the fifth minute. More prolonged interruption of blood flow resulted in severe vasoconstriction as evidenced by a decrease in arterioles diameter from $24.1 \pm 3.7$ $\mu \mathrm{m}$ at baseline to $6.8 \pm 0.5 \mu \mathrm{m}$ at $8 \mathrm{~min}$ of occlusion $(p<0.01$, 
$n=16$ arterioles in 9 mice). Based on these observed changes in blood flow and mitochondrial fragmentation, we selected 5 min as a minimal sufficient duration of common carotid artery occlusion. Therefore, to study reperfusion-dependent mitochondrial fragmentation, the first group of animals $(n=5)$ was subjected to a brief 5 min BCCAO and the second group $(n=5)$ was subjected to a more prolonged 8 min occlusion.

In both groups, mitochondrial fragmentation began to develop during the first $5 \mathrm{~min}$ of occlusion (Fig. $2 B-D, F$ ), and it was linearly correlated with the reduction of blood flow $(r=-0.719$, $p<0.001$; Fig. $2 E, F)$. Indeed, by the end of the 5 min occlusion, the mitochondrial fragmentation score increased from the baseline level of $0.27 \pm 0.06$ to $0.67 \pm 0.06$ (Fig. $2 C, D, F$ ). Reperfusion during the first $3 \mathrm{~min}$ after a brief $5 \mathrm{~min}$ BCCAO resulted in a rapid restoration of blood flow to $81.9 \pm 7.7 \%$ of baseline with a complete recovery by $30 \mathrm{~min}(108.4 \pm 7.29 \%)$ (Fig. $2 E$; black trace). Recovery of blood flow was correlated with recovery of mitochondria tubular structure $(r=-0.346, p<0.05$; Fig. $2 B-$ $D, F)$. Indeed, the fragmentation score significantly decreased from $0.65 \pm 0.05$ at the beginning of reperfusion to $0.41 \pm 0.06$ at $30 \min (p=0.02$; paired $t$ test, $n=5$ mice) (Fig. $2 F$, black trace). In contrast to the brief 5 min BCCAO group, reperfusion in the second group of mice subjected to $8 \mathrm{~min}$ occlusion was incomplete, with blood flow recovering to only $81.8 \pm 8.3 \%$ of baseline at $30 \mathrm{~min}$ of reperfusion and with $91.8 \pm 8.5 \%$ of recovery at 90 min (Fig. 2E, red trace). The $8 \mathrm{~min}$ BCCAO also resulted in a further increase in the mitochondrial fragmentation score to $0.84 \pm 0.06$ at the end of occlusion (Fig. $2 F$, red trace). Moreover, no significant recovery of mitochondrial tubular structure was revealed upon reperfusion with fragmentation score, decreasing to only $0.60 \pm 0.05$ at $90 \mathrm{~min}$ of reperfusion $(p<0.05$ relative to baseline, paired $t$ test, $n=3$ mice), which suggests irreversible fragmentation (Fig. $2 F$, red trace). Together, these findings indicate that neuronal mitochondria in vivo undergo fragmentation in parallel with a loss of blood flow during onset of global cerebral ischemia, and the timing and efficiency of reperfusion are crucial in determining the degree of reversibility in mitochondrial structural changes.

Next, mitochondrial fragmentation in response to global cerebral ischemia seen with two-photon microscopy was verified with quantitative EM analyses. Three sham-operated control urethane-anesthetized Thyl-GFP(M) mice were imaged with two-photon microscopy and then, after confirmation of the intact dendritic structure, were perfusion fixed through the heart. In the other 3 mice, rapid global ischemia was induced on the microscope stage with DC potential and EEG monitoring (Fig. 3A) (Murphy et al., 2008; Risher et al., 2012). Occlusion was accompanied by reduction of blood flow (Fig. $3 B$ ) followed by a rapid SD onset at $6.1 \pm 2.0 \mathrm{~min}$ after beginning of BCCAO (Fig. $3 A$ ). As expected, BCCAO-induced SD invariably beaded dendrites (Fig. 3C), and then mice were immediately perfusion fixed for EM within $12.1 \pm 1.7$ min of occlusion and without any reperfusion. Electron micrographs from neuropil of shamoperated control mice showed intact dendrites with structurally unimpaired mitochondria (Fig. 3D). On the contrary, dendrites from animals subjected to stroke revealed signs of swelling with loss of microtubules and severely swollen mitochondria. Indeed, single-section EM analyses shown that the average cross-section dendritic mitochondria area after BCCAO $\left(0.223 \pm 0.011 \mu \mathrm{m}^{2}\right.$, $n=409$ mitochondria) was significantly larger than in shamoperated control mice $\left(0.062 \pm 0.002 \mu \mathrm{m}^{2}, n=393\right.$ mitochondria) ( $p<0.001$, Mann-Whitney rank sum test; Fig. $3 E, F)$. The largest mitochondria cross-sectional area in control mice was 0.2 $\mu \mathrm{m}^{2}$. In comparison, in mice subjected to BCCAO, $36.4 \%$ of mitochondria had cross-sectional area $>0.2 \mu \mathrm{m}^{2}$ (Fig. $3 F$ ), revealing mitochondrial swelling.

Mitochondrial fragmentation that was first revealed with twophoton microscopy (Fig. 2) was supported with ssTEM. Long filamentous mitochondria have been previously found in dendrites of hippocampal neurons (Popov et al., 2005). Accordingly, every reconstructed dendritic segment (8.67-14.19 $\mu \mathrm{m}$ in length, average $11.86 \pm 0.70 \mu \mathrm{m}, n=7$ ) of cortical neurons from two series obtained from two sham-operated mice had long mitochondrial filaments (Fig. $3 G$ ). Transverse serial sections of seven dendritic segments allow reconstruction of 12 mitochondria with a length of $1.79-13.81 \mu \mathrm{m}$ (average $8.52 \pm 1.34 \mu \mathrm{m}$; Fig. $3 H$ ). It is actually unclear how long these mitochondria were because only two of these mitochondria (2.54 and $4.38 \mu \mathrm{m}$ in length) from these dendritic segments were fully confined within series containing 167 and 203 sections, with the rest extending beyond the first or the last section, or both. In contrast, 11 reconstructed dendritic segments $(6.4-15.67 \mu \mathrm{m}$ in length, average $11.27 \pm$ $0.95 \mu \mathrm{m}$; Fig. $3 G$ ) from two series from two mice subjected to BCCAO had 47 short discrete mitochondria with a length of $0.15-4.74 \mu \mathrm{m}$ (average $1.54 \pm 0.16 \mu \mathrm{m}$; Fig. $3 H$ ). Some of these globular mitochondria were still interconnected by thin mitochondrial segments indicating ongoing fission events known to lead to the fragmentation of filamentous mitochondrial network, which facilitates mitophagy or can result in apoptosis after severe damage (Rugarli and Langer, 2012). Forty of these globular mitochondria $(0.29-4.74 \mu \mathrm{m}$ in length, average $1.53 \pm 0.17 \mu \mathrm{m})$ from 11 dendritic segments were fully reconstructed within 170 and 220 serial sections, with only 7 mitochondria being cut off at the beginning or at the end of the series. Thus, ssTEM confirmed that global ischemia was associated with fragmentation and substantial ultrastructural changes in dendritic mitochondria, not a redistribution of CFP.

\section{Longitudinal imaging of mitochondrial fragmentation in the RBPS model of focal stroke}

Bilateral occlusion of common carotid arterys allows studying the acute phase of ischemia during severe metabolic compromise, but longitudinal studies of the recovery phase are difficult due to high mortality rates and great variability of this model. Therefore, we used the RBPS model of focal stroke, which allows better controlled longitudinal studies of mitochondrial fragmentation in the ischemic core and areas of the tissue located 1.5-2 mm away from the core (Fig. 4A). RBPS resulted in the permanent ischemia in the core area, where RBC velocity was reduced by $87.3 \pm 12.4 \%$ and $94.1 \pm 5.6 \%$ as measured at $30 \mathrm{~min}$ and $3 \mathrm{~h}$, respectively ( $n=16$ blood vessels in 7 mice), whereas in the remote area blood flow remained unaffected (from $8.7 \pm 4.6$ $\mathrm{mm} / \mathrm{s}$ at baseline to $9.3 \pm 5.5$ and to $8.4 \pm 5.0 \mathrm{~mm} / \mathrm{s}$, at $30 \mathrm{~min}$ and $3 \mathrm{~h}$, respectively, $n=19$ blood vessels in 7 mice). In agreement with the data from the global ischemia model with a prolonged 8 min occlusion, severe mitochondrial fragmentation was observed in an injury core with a score that increased from $0.27 \pm$ 0.07 at baseline to $0.77 \pm 0.11$ at $20 \mathrm{~min}$ after $\operatorname{RBPS}(p<0.01, n=$ 7 mice; Figs. $4 B, C, 5 A)$. Mitochondria fragmentation continued to develop as revealed by an increased fragmentation score at $2 \mathrm{~d}$ later $(0.93 \pm 0.05, p<0.001, n=7$ mice $)$. Indeed, we observed no recovery of mitochondrial morphology over 3 weeks. In contrast, in the remote area, mitochondrial fragmentation score gradually increased, reaching significance at $3 \mathrm{~h}$ after RBPS compared with the baseline score (from $0.31 \pm 0.07$ to $0.53 \pm 0.07$, respectively; $p<0.05, n=7$ mice, paired $t$ test; Figs. $4 D, E, 5 B)$. Mitochondrial 

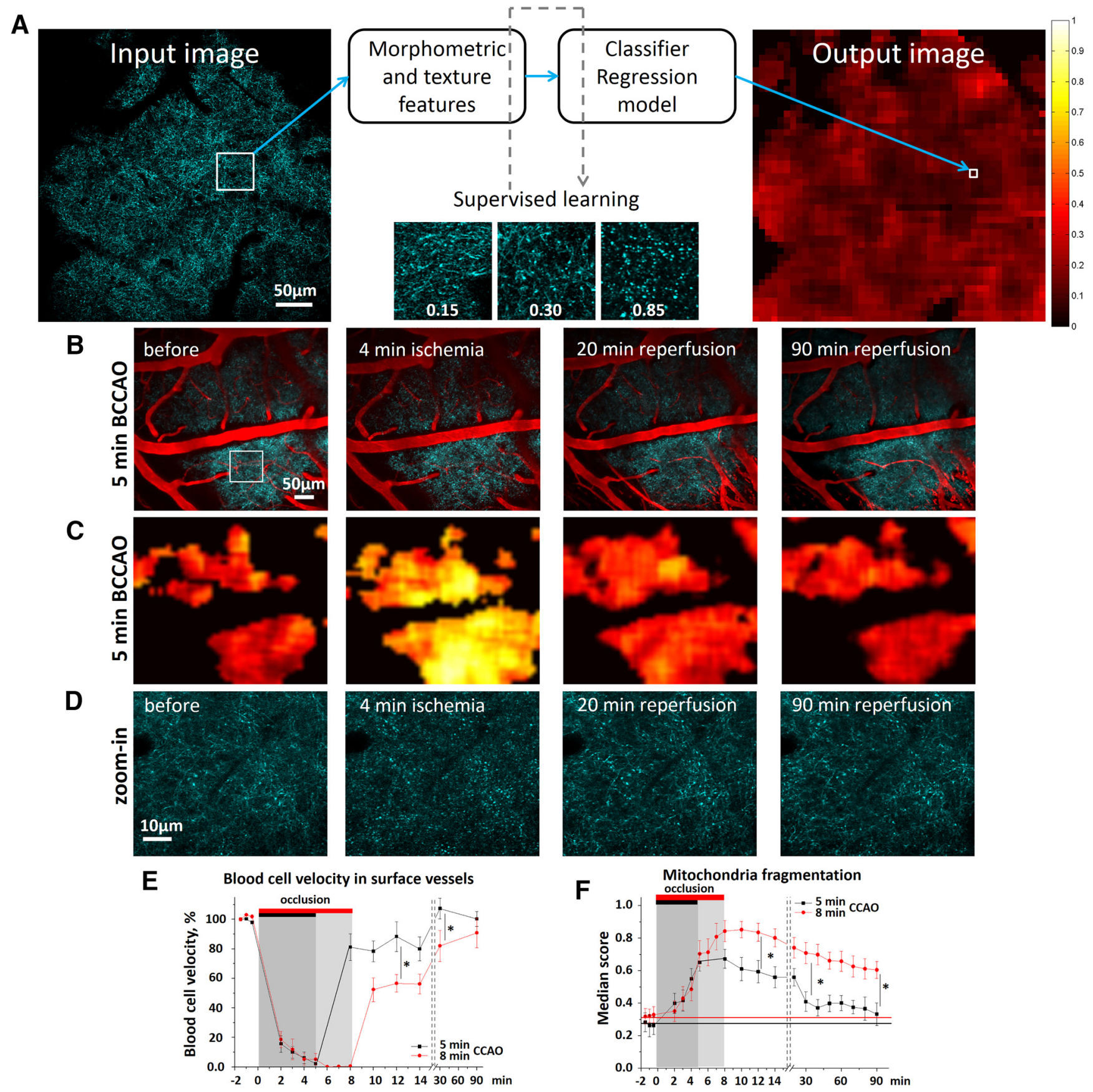

Figure 2. Short-term dynamics of neuronal mitochondria during global ischemia and reperfusion. $A$, Overview of the supervised learning-based quantification method that calculates the degree of fragmentation in a population of neuronal mitochondria from large-scale single-plane images. Morphometric and texture features automatically extracted from a patch and then fed to the classifier and the regression model, previously trained using the exemplar patches scored by an investigator. The regression model assumes the response variable of fragmentation score, whereas the classifier selects regions of interest. The mitochondrial fragmentation score for a single optical section is depicted as a heatmap. The contiguous black regions are non-region of interest (ROI) pixels, as determined by the classifier. $B$, Single optical section image of CFP-labeled neuronal mitochondria (cyan pseudocolor) and cortical vessels (red pseudocolor) before, at 4 min of occlusion, and 20,90 min after reperfusion. $\boldsymbol{C}$, Heatmaps of the fragmentation score from $\boldsymbol{B}$ reveal reversible mitochondrial fragmentation during reperfusion. $\boldsymbol{D}$, Corresponding single-plane image of CFP-labeled mitochondria from the white boxed region shown in B.E, Quantification of changes in average RBC velocity in surface cortical blood vessels before and during 5 and 8 min of $B C C A 0$ and 90 min of reperfusion. Asterisks indicate significant difference between the groups in blood flow at $12 \mathrm{~min}\left(p=0.017, F_{(1,9)}=9.11\right.$, one-way ANOVA; Tukey's post hoc test, $\left.{ }^{*} p<0.05\right)$ and 30 min following reperfusion $\left(p=0.042, F_{(1,9)}=5.88\right.$, one-way ANOVA; Tukey's post hoc test, ${ }^{*} p<0.05$ ). $F$, Mitochondrial fragmentation score before, during 5 and 8 min of BCCAO, and over 90 min following reperfusion. Asterisks indicate significant difference in the mitochondrial fragmentation score between mice subjected to the 5 or 8 min occlusion at 12 min $\left(p=0.018, F_{(1,9)}=8.79\right.$, one-way ANOVA; Tukey's post hoc test, $\left.{ }^{*} p<0.05\right), 30 \mathrm{~min}\left(p=0.011, F_{(1,9)}=10.78\right.$, one-way ANOVA; Tukey's post hoc test, $\left.{ }^{*} p<0.05\right)$, and 90 min following reperfusion $\left(p=0.022, F_{(1,6)}=\right.$ 10.67 , one-way ANOVA; Tukey's post hoc test, $\left.{ }^{*} p<0.05\right)$.

fragmentation continued to rise, attaining a score of $0.79 \pm 0.06$ on day 2 . However, recovery of mitochondrial structure $(0.39 \pm$ $0.07, p=0.52, n=4$ animals) was observed 3 weeks after RBPS. Together, these data indicate that mitochondria are extremely sensitive to the loss of blood flow and can serve as an in vivo indicator of ischemic tissue.

Dendritic beading is an early morphological sign of acute neuronal injury associated with a variety of pathological conditions, 


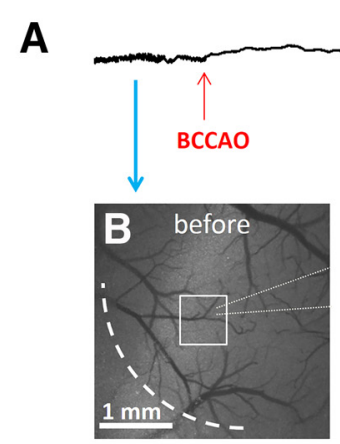

before
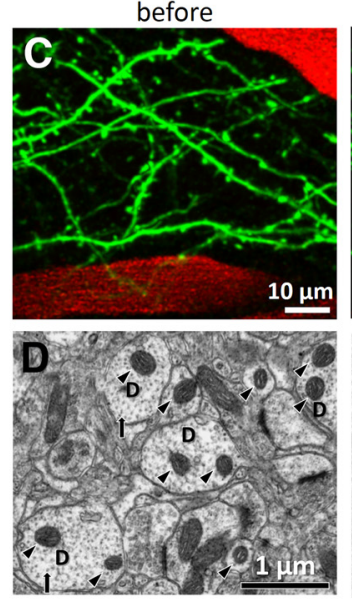

E

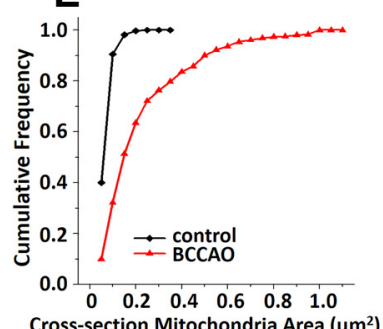

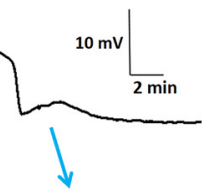

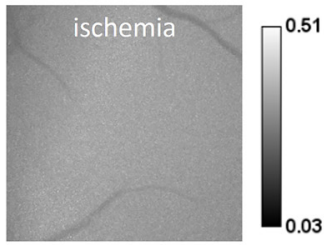

ischemia
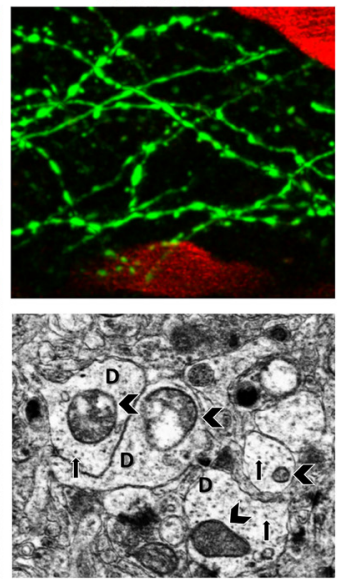

$F$

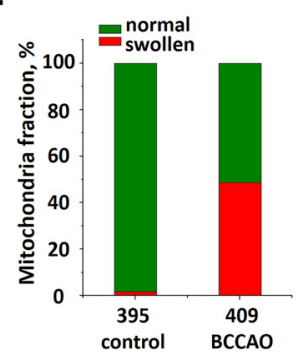

G

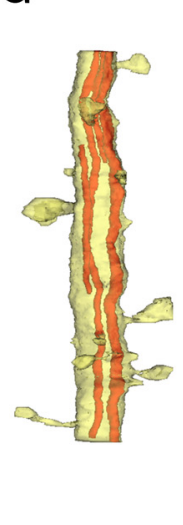

H

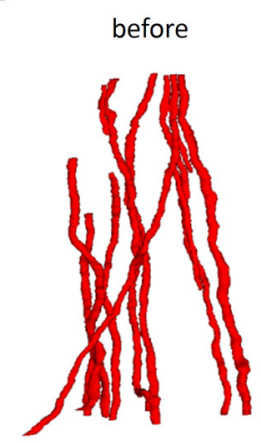

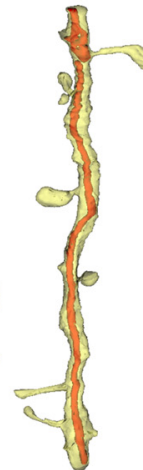

Mitochondria

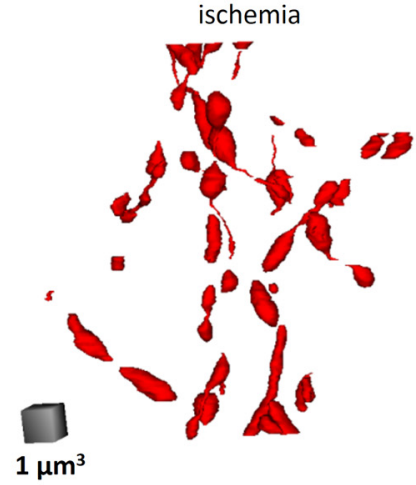

$1 \mu \mathrm{m}^{3}$

ischemia
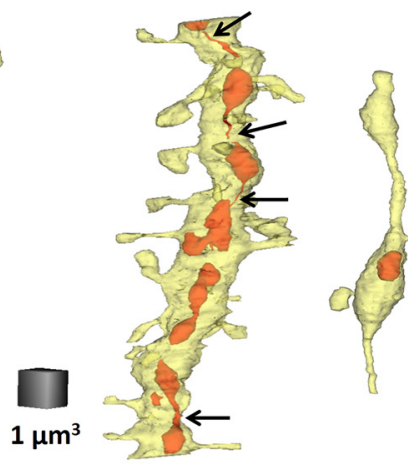

Figure 3. Dendritic beading, mitochondria swelling, and fragmentation during BCCAO. $A$, Recording of the cortical DC EEG from a glass microelectrode. The large negative deflection in the DC potential indicates BCCA0-induced SD. Red arrow indicates beginning of occlusion. Blue arrows indicate approximate time points on the cortical slow DC potential recording when corresponding grayscale images of laser speckle contrast were taken. $\boldsymbol{B}$, Image sequence of laser speckle contrast reveals surface (BF directly below the craniotomy, with regions of high velocity blood flow appearing dark. Loss of blood flow after occlusion is clearly seen. Edge of the craniotomy (dashed line), placement of recording glass microelectrode (dotted line), and two-photon imaging area (square) are indicated in the first image acquired before BCCA0. C, Two-photon image sequence of EGFP-positive dendrites (green) and blood vessels (red; blood plasma labeled with Texas Red dextran) before and after onset of long-lasting BCCAO-induced SD. Dendritic beading precisely coincided with the passage of SD recorded by a microelectrode placed next to imaged dendrites. $D$, Ultrastructural components of dendritic structure in the somatosensory cortex photographed in the vicinity of recording microelectrode $150 \mu \mathrm{m}$ below the pia. Morphologically healthy neuropil in sham-operated mouse (left) had dendrites (D) with intact cytoplasm, arrays of microtubules (arrows), and undamaged mitochondria (arrowheads). Disrupted neuropil after BCCA0 (right) had swollen dendrites $(\boldsymbol{D})$ with watery cytoplasm that contained few remaining microtubules (arrows) and largely swollen mitochondria (chevrons) with some cristae damage. $\boldsymbol{E}$, Cumulative frequency of cross-section mitochondria area obtained in sham-operated (control) and mice subjected to BCCAO. Cross-section mitochondria area was significantly larger in mice after global cerebral ischemia $\left(p<0.0001\right.$; Kolmogorov-Smirnov test). $\boldsymbol{F}$, Presence of mitochondria with cross-sectional area $>0.2 \mu \mathrm{m}^{2}$ (largest cross-sectional area measured in sham mice) indicates BCCA0-induced mitochondrial swelling. The number of mitochondria that were measured in each condition is indicated under each bar. $\mathbf{G}$, Representative 3D reconstructions of large-diameter ( $>1 \mu \mathrm{m})$ and small-diameter $(<1 \mu \mathrm{m})$ dendritic segments from sham-operated and ischemic mice. Dendrites from sham-operated animals contained filamentous (tubular) mitochondria, whereas mitochondria in mice subjected to BCCAO were fragmented. Thin mitochondrial segments that interconnect some of the globular mitochondria in dendrites of ischemic mice (black arrows) imply ongoing fission events. $\boldsymbol{H}$, 3D reconstructions of 12 filamentous mitochondria from 7 dendritic segments from sham-operated mice and $47 \mathrm{globular}$ and swollen mitochondria reconstructed from 11 dendritic segments from ischemic animals.

including ischemia (Hori and Carpenter, 1994; Zhang et al., 2005; Risher et al., 2010). Therefore, we quantified mitochondrial fragmentation and dendritic beading concurrently during the first $3 \mathrm{~h}$ following RBPS in the core and in the remote area using dual transgenic Thy1-MitoCFP $\times$ Thy1-EGFP(M) mice. Similarly to Thyl-mitoCFP mice, mitochondrial fragmentation score in dual transgenic mice increased in the core from $0.34 \pm 0.09$ at baseline to $0.72 \pm 0.11$ at $20 \mathrm{~min}$ after RBPS $(p<0.01$, paired $t$ test, $n=$
5 mice). In contrast to changes in mitochondrial morphology, dendritic injury in the core evolved relatively slow. Under our experimental conditions, only $19.7 \pm 10.9 \%$ of beaded dendrites were found at $20 \mathrm{~min}$ after RBPS ( $p=0.15, n=5$ mice), but most of the dendrites $(78.1 \pm 7.3 \%)$ were beaded by $2 \mathrm{~h}(p<0.001)$ (Fig. $5 C, E$ ). With blood flow largely preserved in the remote areas, it was plausible that dendritic structure in these areas will remain mostly unchanged. Accordingly, dendritic structure remained stable 

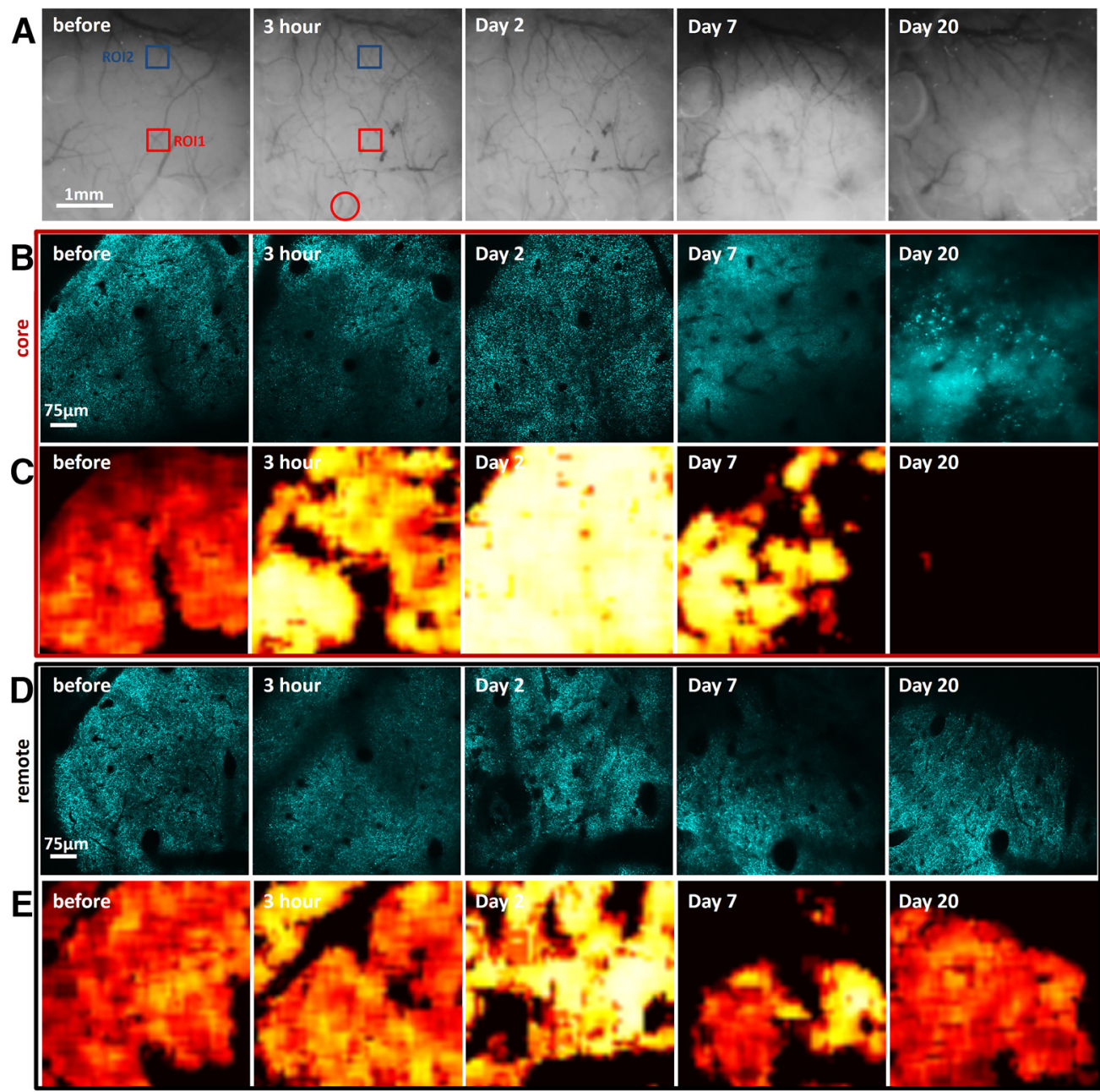

Figure 4. Long-term dynamics of neuronal mitochondria after focal ischemic stroke. $A$, Representative sequence of bright-field images of the superficial blood vessels before and after RBPS. Squares represent regions imaged over time. Red circle represents area illuminated with a green epifluorescent light to induce RBPS. Blood clots are clearly visible in stagnated blood vessels at $3 \mathrm{~h}$ and $2 \mathrm{~d}$ after stroke along with a lesion progression as revealed by changes in the light reflectance at 7 and $20 \mathrm{~d}$ after injury. $\boldsymbol{B}-\boldsymbol{E}$, Corresponding single optical section image sequences of CFP-labeled neuronal mitochondria and heatmaps of the fragmentation score in the core $(B, C)$ and remote $(D, E)$ areas from ROI1 and ROI2 of $A$, respectively. In the core area $20 \mathrm{~d}$ after RBPS, the majority of the patches were not accepted by the classifier due to an absence of recognizable mitochondria resulting in the contiguous black regions as CFP fluorescence became diffused and unstructured.

throughout $3 \mathrm{~h}$ of imaging following RBPS, with the percentage of beaded dendrites equal to $7.3 \pm 5.5 \%$ and $20.5 \pm 8.1 \%$ at $20 \mathrm{~min}$ and 3 h, respectively (Fig. $5 D, F$ ). Together, these data provide strong evidence that mitochondrial structure is very sensitive to the loss of blood flow in contrast to dendritic structure, which was more stable in our RBPS model of focal ischemia.

\section{Reversible fragmentation of dendritic mitochondria in the FLL model}

We observed mitochondria loss in the ischemic core of the focal stroke and irreversible changes in mitochondrial structure after prolonged global ischemia. The loss of mitochondria in focal cerebral ischemia might simply reflect the loss of neurons at the site of ischemic lesion. Subsequently, irreversible mitochondrial fragmentation observed at $90 \mathrm{~min}$ after BCCAO might also be attributed to permanent damage to neuronal somata after prolonged global ischemia. Thus, we decided to limit the damage to dendritic compartment to test whether mitochondrial fragmentation is reversible after moderate injury to dendritic tufts by FLL. FLL was produced by laser ablation in the absence of any photosensitizing agents, such as Rose Bengal. FLL resulted in the loss of
CFP fluorescence and elimination of individual branches of the apical dendrites in a controlled volume (typically 60-530 pl) at the site of injury (Fig. $6 A, B$ ). Spontaneous dendritic regrowth into the lesion site occurred during $7-14 \mathrm{~d}$, and it was correlated $(r=-0.73, p<0.02)$ with restoration of CFP fluorescence (Fig. $6 C-G)$. Interestingly, although FLL induced a significant mitochondrial fragmentation at the perilesion site (Fig. $6 C, D$ ), there were no structural changes in perilesional dendrites (Fig. 6E). Indeed, mitochondrial fragmentation score increased from $0.21 \pm 0.07$ before FLL to $0.52 \pm 0.08$ at $30 \mathrm{~min}$ after FLL at the perilesion site $(p<0.05 ; n=5$ mice; Fig. $6 F)$, whereas there were no changes in the percentage of the beaded dendrites (15.6 \pm $9.7 \%, 30$ min after FLL, $p=0.18$, one-sample $t$ test, $n=5$ mice). Full recovery of mitochondrial structure in the perilesion perimeter of the damaged volume was observed during 1 week (Fig. $6 F)$. Together, these data indicate that localized injury to dendritic compartment that spares neuronal somata leads to only a transient loss of dendrites and their mitochondria. These data further emphasize that mitochondria morphology is easily affected by brain trauma. 
A

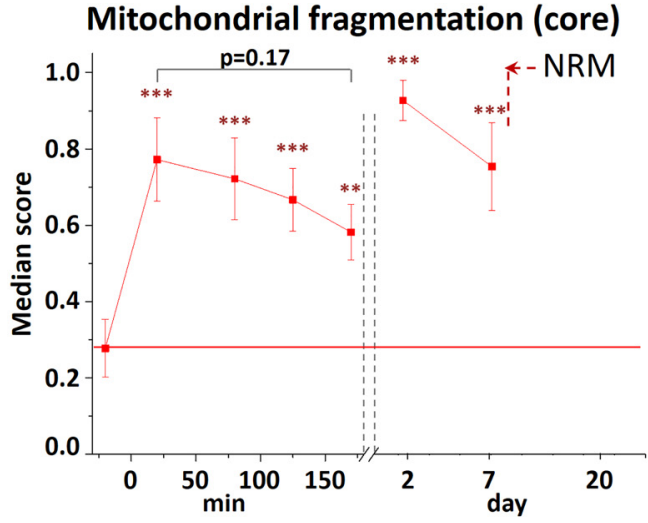

B Mitochondrial fragmentation (remote)

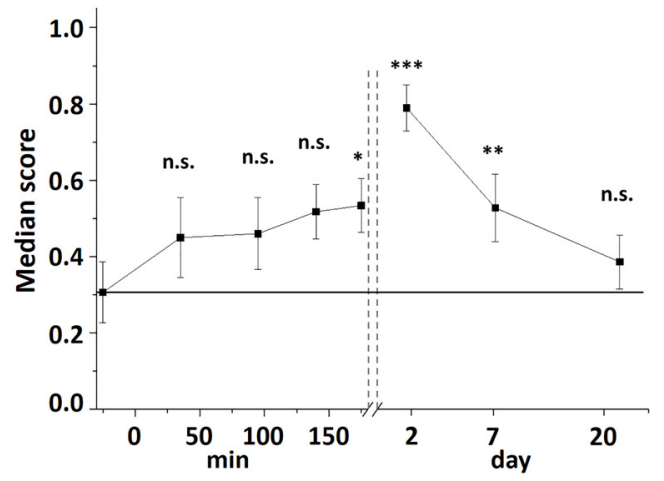

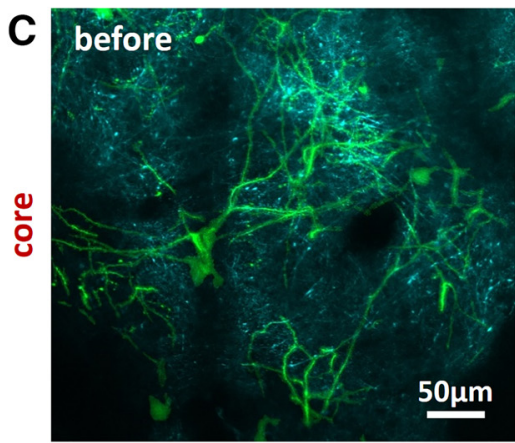

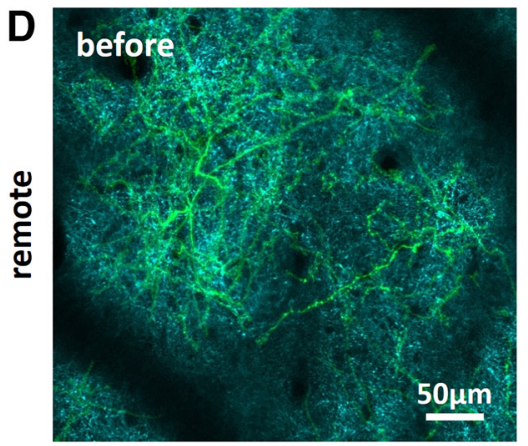

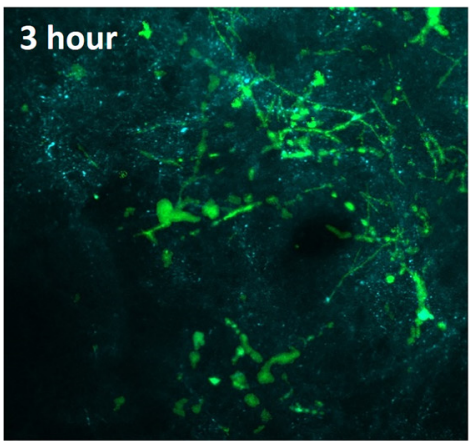

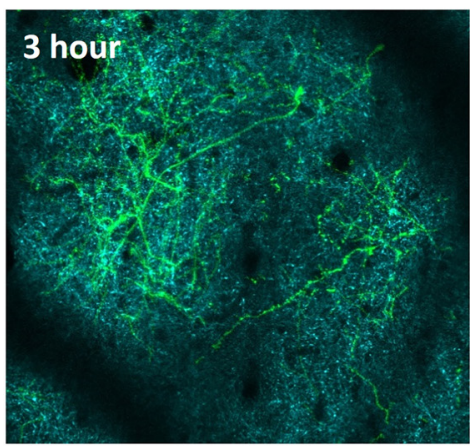

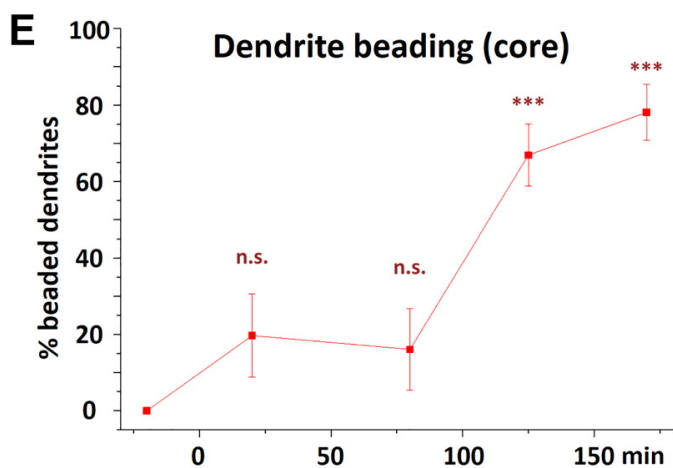

$\mathbf{F}$

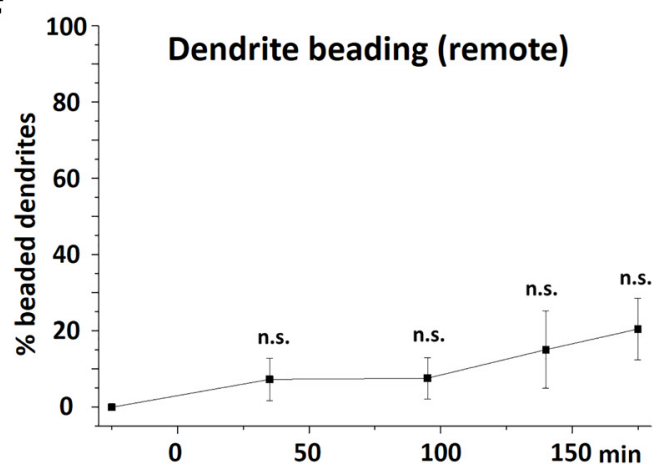

Figure 5. Quantification of dynamics of neuronal mitochondria after focal ischemic stroke. $\boldsymbol{A}, \boldsymbol{B}$, Mitochondrial fragmentation score in the core $(\boldsymbol{A})$ and remote $(\boldsymbol{B})$ areas. ${ }^{*} p<0.05$, significant difference from fragmentation score before stroke (paired $t$ test). ${ }^{* *} p<0.01$, significant difference from fragmentation score before stroke (paired $t$ test). ${ }^{* * *} p<0.001$, significant difference from fragmentation score before stroke (paired $t$ test). At the core, the classifier was not able to indicate ROI beyond $7 \mathrm{~d}$ after injury due to absence of recognizable mitochondria in the image with corresponding section marked as NRM (no recognizable mitochondria) on the graph. C, D, Color-coded overlay of a single optical plane image of neuronal mitochondria (cyan) and a maximum intensity projection image of dendritic tuft (green) from dual transgenic Thy1-mitoCFP $\times$ Thy1-EGFP(M) mice in the core $(\boldsymbol{C})$ and the remote $(\boldsymbol{D})$ area before and at $3 \mathrm{~h}$ after RBPS. $\boldsymbol{E}, \boldsymbol{F}$, Time course of dendritic beading in the core $(\boldsymbol{E})$ and the remote area $(\boldsymbol{F}) .{ }^{* *} p<0.001$, significant difference from the control time point before RBPS (one-sample $t$ test).

Reversible fragmentation of mitochondria in intact dendrites after the MPD

Next, we decided to establish a mild brain injury model in which we could examine dynamics of mitochondrial fragmentation in intact dendritic compartment. We chose to induce mild injury by means of a photo-damage because the degree of injury could be tightly controlled by laser intensity and exposure time. First, we found that neuronal mitochondria and dendrites exhibited different sensitivity to laser light intensity. At the infrared laser energy levels ranging from 5 to $20 \mu \mathrm{J}$ (as measured in the objective focal plane), both mitoCFP and dendritic YFP fluorescence was lost. However, at the lower laser energy level from 0.5 to $1 \mu \mathrm{J}$, dendrites remained intact whereas mitochondria became clearly fragmented. Finally, at the laser energy ranging from 0.05 to 0.40 $\mu \mathrm{J}$, both mitochondria and dendrites remained intact. Therefore, we selected the energy range between 0.5 and $1 \mu \mathrm{J}$ to determine mitochondrial fragmentation and recovery in intact dendrites during injury inflicted by MPD.

MPD was induced in a small cortical volume (typically $165 \times$ $165 \times 100 \mu \mathrm{m})$. Within minutes after MPD induction, mitochondria were found to become fragmented in the photodamaged region (Fig. $7 A, B$, white box). Indeed, mitochondrial fragmentation score increased from $0.23 \pm 0.08$ to $0.76 \pm 0.09$ in the first $30 \mathrm{~min}$ after injury $(p<0.01 ; n=6$ mice; Fig. $7 C$ ). The fragmentation score declined over the next several days, reaching preinjury level at $7 \mathrm{~d}$ after laser exposure $(p=0.29$, paired $t$ test, $n=6$ mice). Notably, the fragmentation did not extend to the surrounding tissue $(0.21 \pm 0.05$ before MPD vs $0.35 \pm 0.06$ at 30 

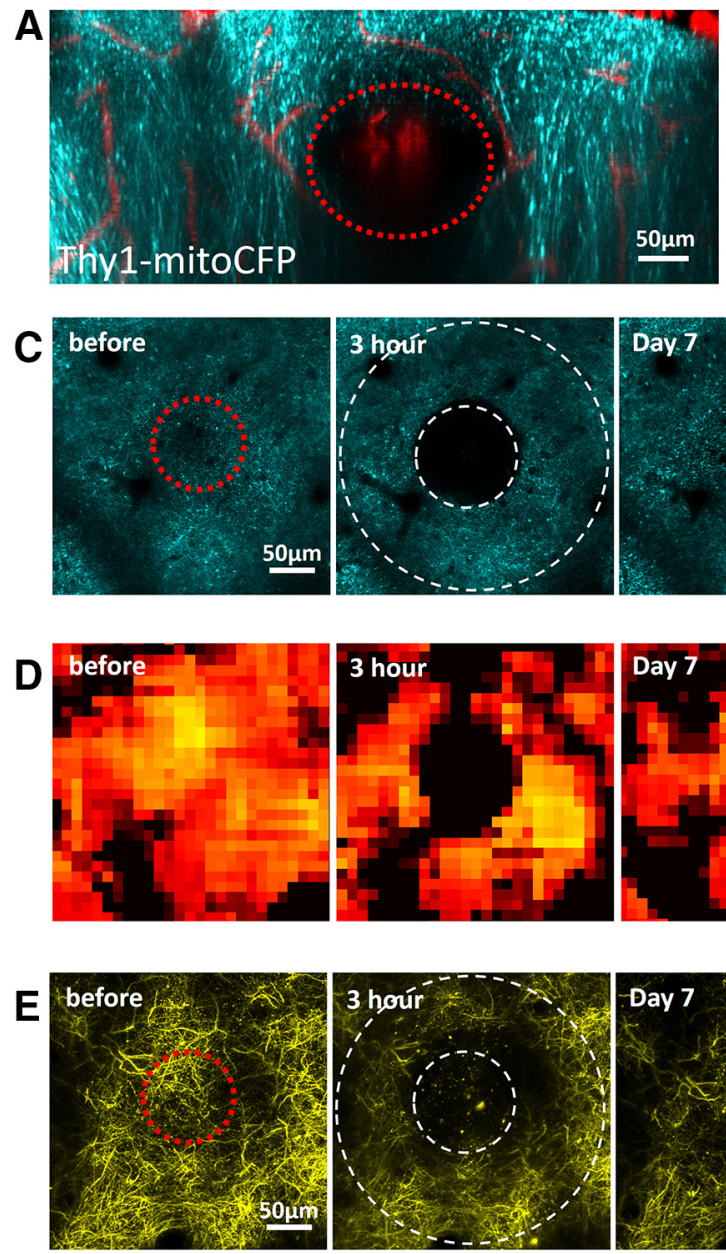

B
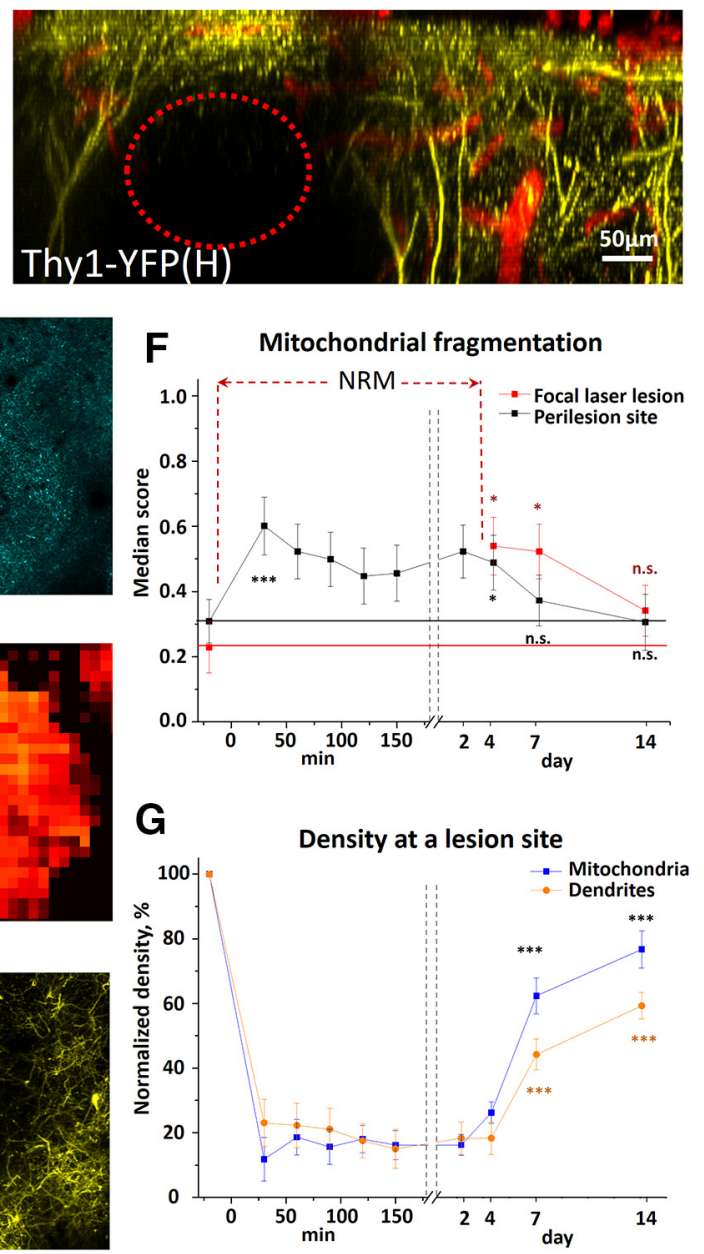

Figure 6. Long-term dynamics of neuronal mitochondria and dendritic structural integrity after moderate FLL. $\boldsymbol{A}, \boldsymbol{B}$, Maximum intensity projection images along the $z$-axis after FLL reveal complete loss of (FP and YFP fluorescence at the lesion site (red dashed circles) in somatosensory cortex of Thy1-mitoCFP $(\boldsymbol{A})$ and Thy1-YFP $(\boldsymbol{B})$ mice. $\boldsymbol{C}, \boldsymbol{D}$, Single optical section image sequences of CFP-labeled neuronal mitochondria $(\boldsymbol{C})$ and heatmaps of the fragmentation score $(\boldsymbol{D})$ reveal a loss of CFP signal at the lesion site and mitochondrial fragmentation at the perilesion site. Red dashed circle before FLL represents a laser target area. Two white dashed circles at $3 \mathrm{~h}$ after FLL represent the lesion site surrounded by the perilesion area (C).E, Maximum intensity projection image series showing dendritic injury at $3 \mathrm{~h}$ after FLL and spontaneous regrowth of dendrites to the lesion site by day 7.F, Mitochondrial fragmentation score at the lesion and perilesion site. At the lesion site, the classifier indicated ROI only by fourth day after FLL due to absence of identifiable mitochondria (NRM) in the image. ${ }^{*} p<0.05$, significant difference from the control time point before FLL (paired $t$ test). ${ }^{* * *} p<0.001$, significant difference from the control time point before FLL (paired $t$ test). $G$, Average normalized density of neuronal mitochondria and dendritic tuft at a lesion site indicates recovery of mitochondria and dendrites over time after FLL. ${ }^{* * *} p<0.001$, significant difference from $3 \mathrm{~h}$ time point after FLL (paired $t$ test).

min after MPD; $p=0.10 ; n=6$ mice; Fig. $7 D)$. To define spatial distribution of fragmented mitochondria over time, we generated digital surfaces over heatmap pixels with a score $>0.6$. Volume containing fragmented mitochondria significantly shrank from $0.49 \pm 0.04 \mu \mathrm{m}^{3}$ at $30 \mathrm{~min}$ after MPD to $0.17 \pm 0.05 \mu \mathrm{m}^{3}$ on day 4 after injury (Fig. $7 E$ ). These findings suggest that refusion (and/or replacement) of fragmented mitochondria in vivo is a relatively slow process that may take several days.

As mentioned above, MPD did not trigger any pathological changes in dendritic structure, such as beading either acutely or over 2 weeks following MPD (Fig. 7F). However, MPD resulted in a significant decrease in dendritic spine density from $0.44 \pm$ $0.07 \mu \mathrm{m}$ before to $0.32 \pm 0.05 \mu \mathrm{m}$ at $2 \mathrm{~d}$ after MPD $(p<0.01$, $n=5$ mice; Fig. $7 G$ ). Spine density remained declined at day 4 $(0.37 \pm 0.02 \mu \mathrm{m} ; p<0.01, n=5)$ but recovered by the end of 1 week. This recovery of dendritic spine density was paralleled by recovery of tubular mitochondrial structure, suggesting a novel link between mitochondria integrity and spine turnover in the adult brain.

A brief summary of our findings is presented in Figure 8.

\section{Discussion}

These findings are the first to show that in vivo neuronal mitochondrial fragmentation occurs within minutes of injury onset and it is either localized in the case of mild or moderate damage, or spreads gradually in the case of severe injury. Mitochondrial structural changes are accompanied by dendritic damage during severe global ischemia and in the core of focal injury. Yet, during mild trauma or in the areas located far away from the injury core, dendrites responded differently from mitochondria, remaining intact while mitochondrial fragmentation occurred. Over time, mitochondria were able to regain their unfragmented morphology in dendrites that were spared from terminal injury. The present work provides the first direct in vivo demonstration of such heterogeneous sensitivity to the injury between dendrites and their mitochondrial organelle.

Mitochondria are very dynamic organelles that can move within dendrites to the site of active synapses ( $\mathrm{Li}$ et al., 2004; Chang et al., 2006) and undergo fusion and fission to maintain optimal morphology to match specific bioenergetic demands 
A

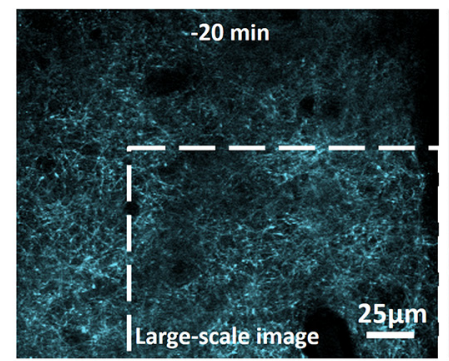

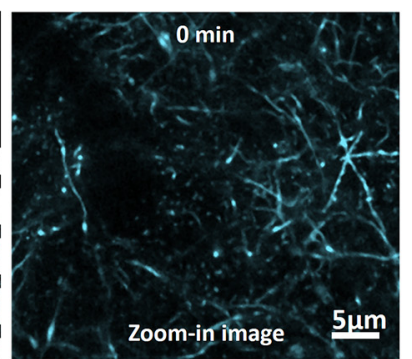
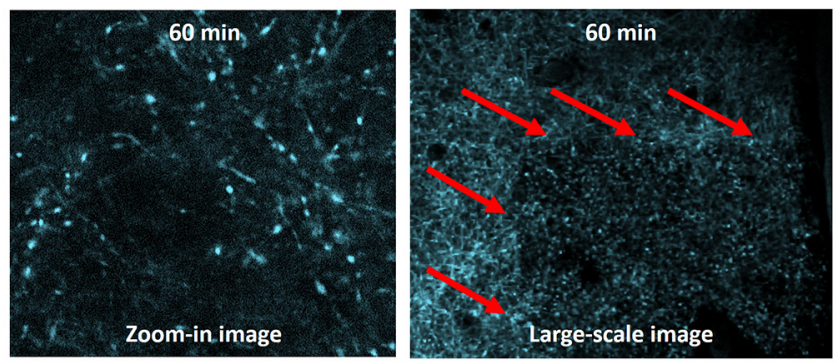

B

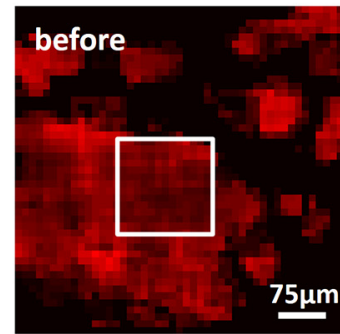

C
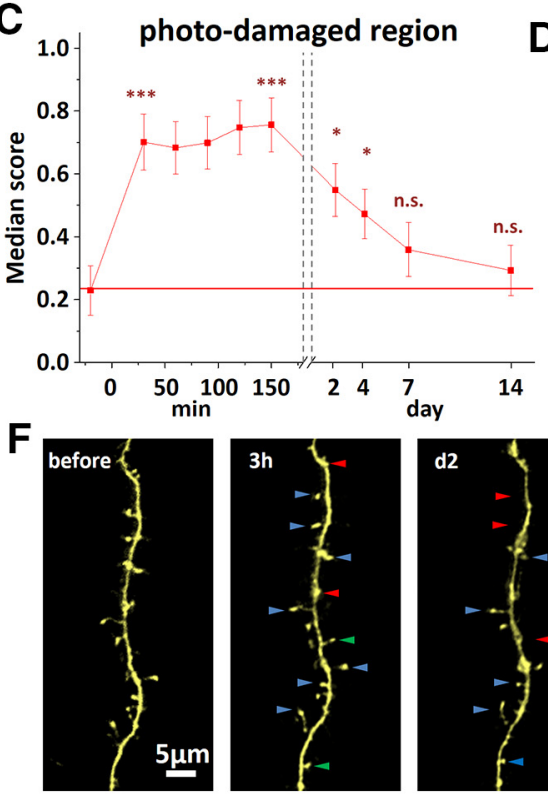

Mild photo-damage

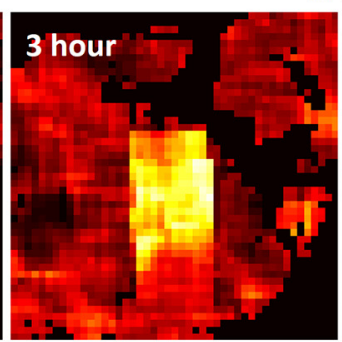

D

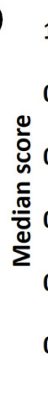

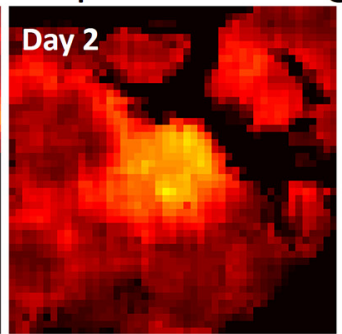

non-damaged region
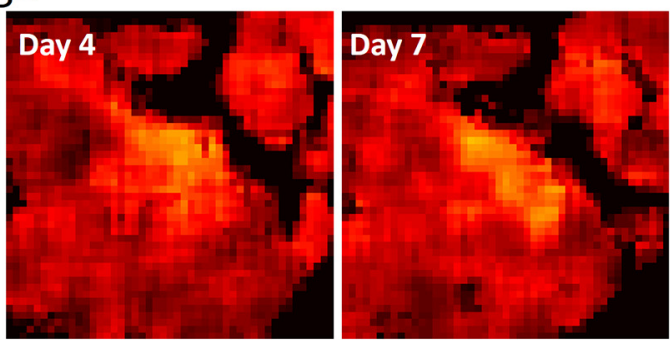

E

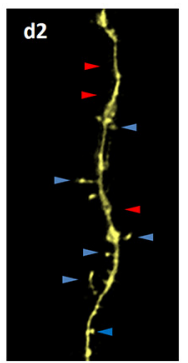

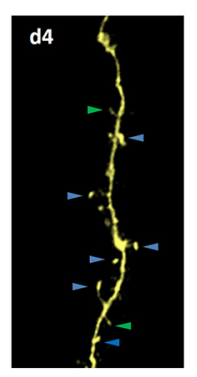

- Stable

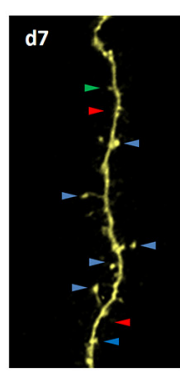

Gained

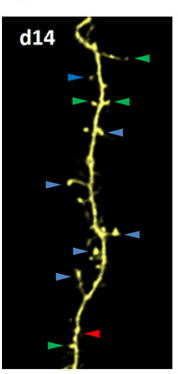

- Lost
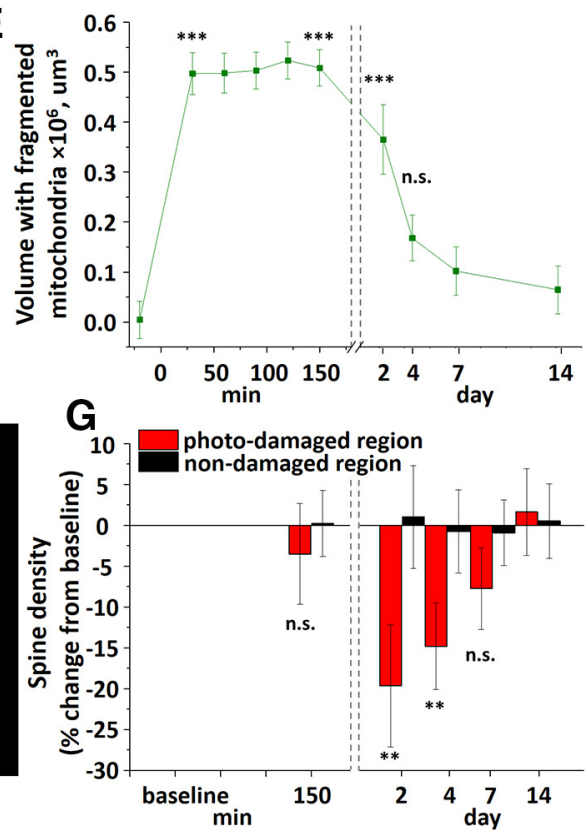

Figure 7. Dendritic structural integrity and neuronal mitochondria dynamics after MPD. A, Low-magnification large-scale image of CFP-labeled mitochondria and corresponding highmagnification zoom-in images at the middle of the white boxed MPD area (left) before and after injury. Red arrows at the large scale image shown to the right indicate sharp borders between regions with intact and fragmented mitochondria at $60 \mathrm{~min}$ after MDP. B, Heatmaps of mitochondrial fragmentation score after MPD induced in a white boxed area (left) reveal transient mitochondrial fragmentation in the MPD area with intact mitochondria structure in surrounding region. C, Quantification of mitochondrial fragmentation score over time in MPD region shows significant fragmentation that persisted for $4 \mathrm{~d}$ after MPD. ${ }^{*} p<0.05$, significant difference from control time point before MPD (paired $t$ test). ${ }^{* * *} p<0.001$, significant difference from control time point before MPD (paired $t$ test). D, Quantification of mitochondrial fragmentation score in adjacent nondamaged region reveals no significant mitochondrial fragmentation. $\boldsymbol{E}$, Average volume of cortex with fragmented neuronal mitochondria after MPD quantified over time from several minutes to $14 \mathrm{~d}$ after injury. ${ }^{* * *} p<0.001$, significant difference from the time point before MPD (paired $t$ test). $\boldsymbol{F}$, In vivo time-lapse imaging of dendritic segment acquired over 2 weeks in MPD area showing stable, gained, and lost dendritic spines as depicted by blue, green, and red arrowheads, respectively, between consecutive time points. G, Summary from 5 mice showing a transient decrease in spine density in MPD area with no changes in spine density in surrounding nondamaged area. ${ }^{* *} p<0.01$, significant difference from control time point before MPD (paired $t$ test).

(Chen et al., 2005; Parone et al., 2008). Fission and fusion of mitochondria are controlled by specific proteins. It was shown that transient cerebral ischemia causes upregulation of two major players, the fission dynamin-related protein 1 (Drp1) and the fusion protein optic atrophy 1 (Opal), in the ischemic penumbra peaking at $2 \mathrm{~d}$ after stroke (Liu et al., 2012). Fusion and fission are necessary to retain healthy mitochondrial population through fusion, which is thought to maintain mitochondrial bioenergetics, and fission, which partitions injured mitochondria from healthy mitochondrial network (Twig et al., 2008; Mouli et al., 2009). Upregulation of Drp1 and Opal after stroke may indicate increased fission and fusion events in the attempt for mitophagy and cell survival. Here, using morphometric analysis of mitochondria, we were able to accurately evaluate dynamic changes in the mitochondrial tubular-to-globular ratio after cortical injuries. When damage was limited to dendritic compartments and neuronal somata were not affected, as in the core of focal laserlesion and MPD models, or in the remote cortical areas away 


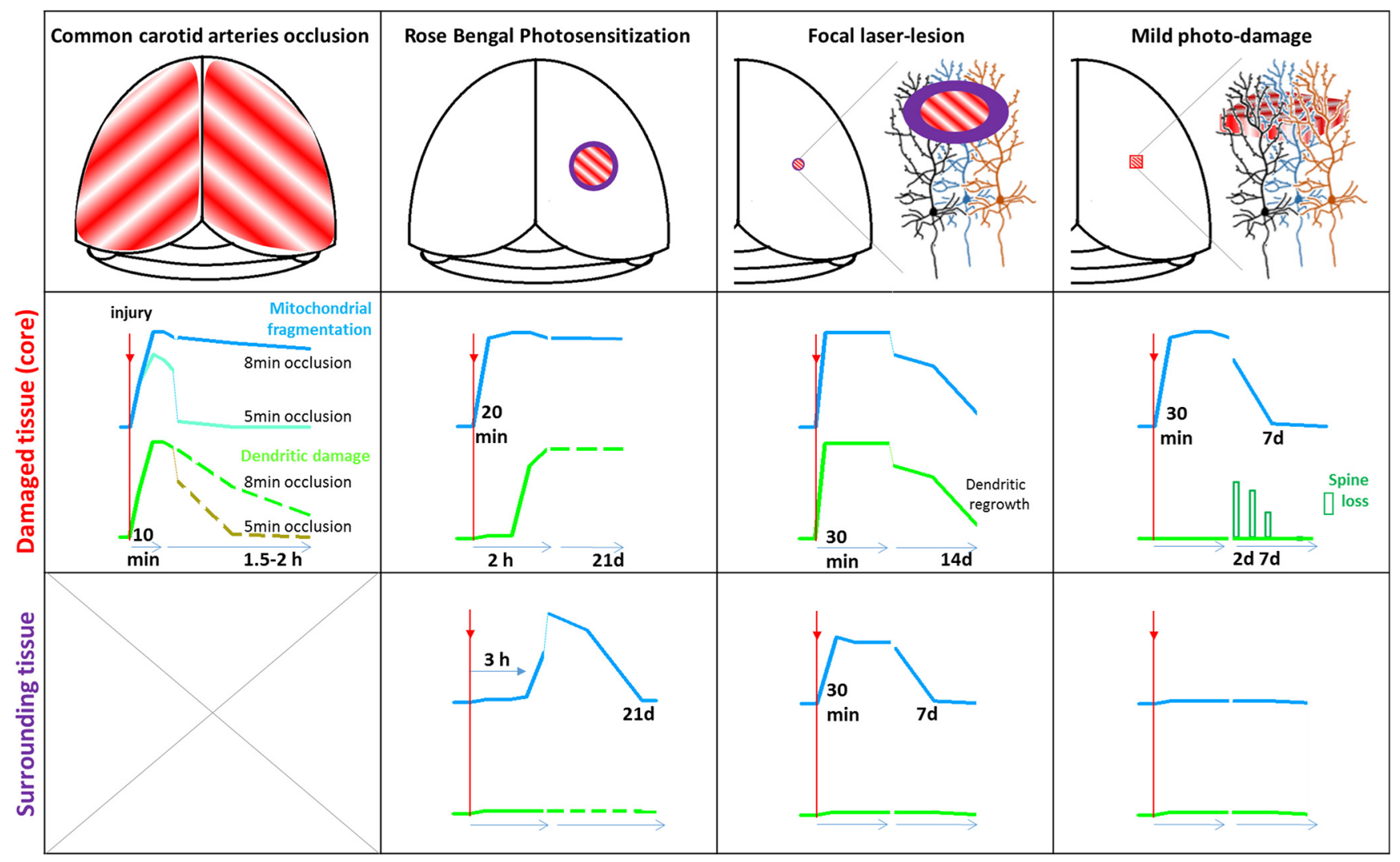

Figure 8. Summary of the study. In four injury models (first row), a time course of mitochondrial fragmentation (blue line) and dendritic damage (green line) is shown in the injury core (second row) and surrounding tissue (third row). The down-up direction of $y$-axis represents amount of dendritic injury and mitochondrial fragmentation as measured at different time points indicated at $x$-axis. The time points indicate significant changes. Solid line drawings represent findings of this study. Dashed line indicates data from pilot experiments or previously published results. In a model of global ischemia (first column), mitochondrial fragmentation and dendritic beading demonstrate similar kinetics in response to the loss of blood flow, but the time course of recovery during reperfusion is different in the case of a prolonged $8 \mathrm{~min}$ occlusion. Green dashed line indicates approximate time course of dendritic recovery when beading subsided by $\sim 2 \mathrm{~h}$ (Risher et al., 2012). After a shorter 5 min occlusion, which presumably resulted in a milder metabolic compromise, mitochondria structure swiftly recovered (cyan line) in parallel to the recuperation of dendritic structure (olive line) (Murphy et al., 2008; Risher et al., 2012). In the core of our RBPS model (second column) of focal stroke, mitochondria have fragmented rapidly, whereas dendritic beading, gated by the degree of ischemia as blood flow stayed declined, developed during the next $2 \mathrm{~h}$. Both mitochondrial fragmentation and dendritic beading persisted in the core for $21 \mathrm{~d}$. In contrast, in remote areas, mitochondrial fragmentations gradually increased by $3 \mathrm{~h}$ and continued to increase by $2 \mathrm{~d}$ after RBPS and then recovered by $21 \mathrm{~d}$, whereas dendrites remained unchanged. In the core of laser-lesion model (third column), both dendrites and mitochondria were rapidly injured by targeted laser irradiation, whereas neuronal somata were not. Dendritic regrowth detected at $7 \mathrm{~d}$ after injury resulted in recovery of dendrites and their mitochondria organelles by $\sim 14 \mathrm{~d}$ after trauma. No dendritic beading was detected at the perilesion zone, whereas mitochondrial fragmentation was significant by $30 \mathrm{~min}$ but recovered by $7 \mathrm{~d}$ after trauma. In the core of the MPD model (fourth column), mitochondria were fragmented by 30 min after laser-induced trauma but recovered by $7 \mathrm{~d}$ after injury. Dendrites were not affected, but dendritic spine density significantly decreased by $2 \mathrm{~d}$ after trauma with recovery to the baseline by $7 \mathrm{~d}$. No mitochondrial or dendritic structural changes occurred in the surrounding tissue. Together, our results demonstrate that mitochondrial structure is very sensitive to the tissue damage in animal models of injury. Mitochondrial fragmentation can be spontaneously reversible in ischemic and traumatic brain injuries. Our data highlight mitochondria as a potential therapeutic target.

from the core of focal stroke model, we have shown unequivocal recovery of tubular mitochondrial structure. The slow time course of this recovery over several days to weeks suggests that it mainly occurred by replacing damaged mitochondria with new organelles formed in those neuronal compartments that were spared from the injury. Similar time course of mitochondrial structural recovery was observed in the core of focal laser lesion; notably, it co-occurred with spontaneous regrowth of dendrites. Indeed, accumulating evidence indicates that the endogenous neuroprotective response to cerebral ischemia induces mitochondrial biogenesis that creates new functional mitochondria (Yin et al., 2008; Anne Stetler et al., 2013). Interestingly, recovery of mitochondria after MPD was paralleled by recovery of dendritic spine density, suggesting that these two events are closely related as mitochondria are thought to dock in an activitydependent manner near dendritic spines to support synaptic transmission (Li et al., 2004; Chang et al., 2006). Hence, it appears that postinjury stimulation of mitochondrial recycling and recovery may play a major role in neuronal survival and restoration of synaptic connectivity and could become a potential therapeutic target.

Conceivably, mitochondrial fragmentation observed in our injury models involves rapid fission-like events. Previously, fission of mitochondria was detected with live confocal microscopy imaging in cultured cortical neurons following oxygen-glucose deprivation (Wappler et al., 2013) and with EM following middle cerebral artery occlusion in mice (Barsoum et al., 2006). A recent histological study by Owens et al. (2015) confirmed these EM observations in brains of mice perfusion-fixed at several time points after common carotid artery occlusion-induced global ischemia. Interestingly, widespread fission of neuronal mitochondria was detected in all hippocampal subregions, but mitochondria were able to re-fuse in ischemia-resistant CA3 and dentate gyrus neurons, suggesting that increased fusion might be neuroprotective in these cells. Here, using ssTEM, we revealed mitochondrial fragmentation after BCCAO and applied realtime in vivo imaging to show that fragmentation developed rapidly within $5 \mathrm{~min}$ after occlusion. Moreover, once triggered by 
noxious stimuli, fragmentation continued to develop in the BCCAO model, as well as in all other injury models we studied. Yet, in contrast to prolonged $8 \mathrm{~min} \mathrm{BCCAO}$, mitochondria were able to re-fuse by $30 \mathrm{~min}$ after a brief $5 \mathrm{~min}$ occlusion. To the best of our knowledge, these are the first in vivo experiments to show such fast reversible perturbation in mitochondrial structure in response to ischemia-induced injury. It is conceivable that the balance between excessive mitochondrial fragmentation and refusion after ischemia may underlie transition from injury to repair in tissue at risk of permanent brain damage, but delayed neuronal death was not evaluated in our study, which warrants future experiments to address this issue.

Previous studies have shown that excessive mitochondrial fragmentation causes increased production of reactive oxygen species, cytochrome $c$ release, and apoptosis (Youle and Karbowski, 2005; Knott et al., 2008; Anne Stetler et al., 2013). Lack of oxygen during ischemia or trauma inhibits mitochondrial oxidative phosphorylation, leading to mitochondrial depolarization and morphological disruption. Indeed, inhibition of mitochondrial oxidative metabolism with chemical treatment inevitably results in mitochondrial fragmentation (Benard et al., 2007; Liot et al., 2009). Mitochondrial depolarization (e.g., in the presence of electron transport chain uncoupling drugs) elicits mitochondrial fission (Ishihara et al., 2003; Meeusen et al., 2004). A fission event by itself can result in mitochondrial depolarization, and then depolarized mitochondria can be selectively disposed by autophagy (Twig et al., 2008). In this respect, widespread mitochondrial fragmentation detected in our models of acute neurological disorders could signify the cellular response to increased number of injured mitochondria that must be eliminated.

In their pioneering in vivo work, Liu and Murphy (2009) used two-photon imaging of the mitochondrial membrane potential $\left(\Delta \psi_{\mathrm{m}}\right)$ with rhodamine 123 during global ischemia. In agreement with brain slice studies (Bahar et al., 2000), they found that $\Delta \psi_{\mathrm{m}}$ depolarization coincided with SD and occurred within $\sim 90 \mathrm{~s}$ of BCCAO. The $\Delta \psi_{\mathrm{m}}$ depolarization was cyclosporine A sensitive, indicating activation of the mitochondrial permeability transition pore, which plays an important role in delayed neuronal death. SD also triggers dendritic beading and accelerates neuronal injury (Kirov, 2014), but beading and mitochondrial depolarization during SD represent two mechanistically separable pathways as blocking $\Delta \psi_{\mathrm{m}}$ depolarization in vivo with cyclosporine A did not affect dendritic beading (Liu and Murphy, 2009). Similarly, in cultured neurons, glutamate excitotoxicity-induced dendritic beading and mitochondrial dysfunction (depolarization and structural collapse into rounded/swollen structures) are independent processes, despite their simultaneous occurrence (Greenwood et al., 2007). Indeed, SD-induced dendritic beading results from water accumulation (Kirov et al., 2004; Andrew et al., 2007) and involves, at least in part, activation of select chloride-coupled neuronal cotransporters (Steffensen et al., 2015; Sword et al., 2016). Studies have shown that the collapse of mitochondrial structure is a consequence of calcium overload (Pivovarova et al., 2004) and water accumulation, which are both present during SD (Greenwood et al., 2007). Accordingly, using $\mathrm{EM}$, we demonstrated that SD-beaded dendrites were swollen and contained watery cytoplasm with swollen mitochondria. This is in agreement with previous ultrastructural studies of cortical neurons that revealed swollen dendrites and mitochondria after only 5 or $10 \mathrm{~min}$ of global ischemia without reperfusion (Tomimoto and Yanagihara, 1992, 1994). A rupture of the outer mitochondrial membrane and release of apoptotic proteins may be one of the possible harmful consequences of such excessive mitochondrial swelling (Brustovetsky et al., 2002).

Gradual development of dendritic beading was observed over $2 \mathrm{~h}$ in the core of RBPS model. Although the cortical DC potential was not recorded, the slow degeneration of dendritic structure is consistent with the lack of SD because SD would rapidly bead dendrites and dramatically accelerate dendritic injury (Murphy et al., 2008; Risher et al., 2010). Without recurrent SDs, beading is gated by the degree of ischemia as a flowing capillary $\sim 80 \mu \mathrm{m}$ away could maintain dendritic structure in the ischemic tissue (Zhang and Murphy, 2007), whereas arterioles can supply oxygen beyond $>100 \mu \mathrm{m}$ (Kasischke et al., 2011). It is conceivable that local residual blood flow in the irradiated core of our RBPS model would initially support dendrites, whereas gradual loss of dendritic structure would parallel a gradual loss of flowing capillaries. It should be noted that, without SD, severely metabolically compromised dendrites ultimately will bead due to the cation influx driven by Gibbs-Donnan forces and insufficient cation efflux caused by inhibition of ATP-dependent sodium pump (Dreier et al., 2013). Such mechanism is different from mechanism of rapid SD-induced dendritic beading (Steffensen et al., 2015; Sword et al., 2016). In contrast, rapid mitochondrial fragmentation in the core of RBPS model reflects high sensitivity of mitochondrial structure to the loss of blood flow and lack of oxygen compared with the dendrites.

In conclusion, we present in vivo evidence of rapid loss and relatively slow recovery of dendritic mitochondrial structural integrity in several models of acute neurological disorders. Because mitochondrial structural rearrangements can influence neuronal function and affect neural pathological outcomes, we expect that novel therapeutic approaches targeting the mitochondrial organelle will benefit from these in vivo experimental insights into injury-induced mitochondrial dynamics.

\section{References}

Abramov AY, Duchen MR (2008) Mechanisms underlying the loss of mitochondrial membrane potential in glutamate excitotoxicity. Biochim Biophys Acta 1777:953-964. CrossRef Medline

Andrew RD, Labron MW, Boehnke SE, Carnduff L, Kirov SA (2007) Physiological evidence that pyramidal neurons lack functional water channels. Cereb Cortex 17:787-802. CrossRef Medline

Anne Stetler R, Leak RK, Gao Y, Chen J (2013) The dynamics of the mitochondrial organelle as a potential therapeutic target. J Cereb Blood Flow Metab 33:22-32. CrossRef Medline

Bahar S, Fayuk D, Somjen GG, Aitken PG, Turner DA (2000) Mitochondrial and intrinsic optical signals imaged during hypoxia and spreading depression in rat hippocampal slices. J Neurophysiol 84:311-324. Medline

Barsoum MJ, Yuan H, Gerencser AA, Liot G, Kushnareva Y, Gräber S, Kovacs I, Lee WD, Waggoner J, Cui J, White AD, Bossy B, Martinou JC, Youle RJ, Lipton SA, Ellisman MH, Perkins GA, Bossy-Wetzel E (2006) Nitric oxide-induced mitochondrial fission is regulated by dynamin-related GTPases in neurons. EMBO J 25:3900-3911. CrossRef Medline

Benard G, Bellance N, James D, Parrone P, Fernandez H, Letellier T, Rossignol R (2007) Mitochondrial bioenergetics and structural network organization. J Cell Sci 120:838-848. CrossRef Medline

Brustovetsky N, Brustovetsky T, Jemmerson R, Dubinsky JM (2002) Calcium-induced cytochrome c release from CNS mitochondria is associated with the permeability transition and rupture of the outer membrane. J Neurochem 80:207-218. CrossRef Medline

Brustovetsky T, Li V, Brustovetsky N (2009) Stimulation of glutamate receptors in cultured hippocampal neurons causes $\mathrm{Ca}^{2+}$-dependent mitochondrial contraction. Cell Calcium 46:18-29. CrossRef Medline

Chan DC (2006) Mitochondria: dynamic organelles in disease, aging, and development. Cell 125:1241-1252. CrossRef Medline

Chandrasekaran K, Hazelton JL, Wang Y, Fiskum G, Kristian T (2006) Neuron-specific conditional expression of a mitochondrially targeted 
fluorescent protein in mice. J Neurosci 26:13123-13127. CrossRef Medline

Chang DT, Honick AS, Reynolds IJ (2006) Mitochondrial trafficking to synapses in cultured primary cortical neurons. J Neurosci 26:7035-7045. CrossRef Medline

Chen H, Chomyn A, Chan DC (2005) Disruption of fusion results in mitochondrial heterogeneity and dysfunction. J Biol Chem 280:26185-26192. CrossRef Medline

Chen S, Tran S, Sigler A, Murphy TH (2011) Automated and quantitative image analysis of ischemic dendritic blebbing using in vivo 2-photon microscopy data. J Neurosci Methods 195:222-231. CrossRef Medline

Dirnagl U (2012) Pathobiology of injury after stroke: the neurovascular unit and beyond. Ann N Y Acad Sci 1268:21-25. CrossRef Medline

Dreier JP, Isele T, Reiffurth C, Offenhauser N, Kirov SA, Dahlem MA, Herreras $O$ (2013) Is spreading depolarization characterized by an abrupt, massive release of Gibbs free energy from the human brain cortex? Neuroscientist 19:25-42. CrossRef Medline

Dunn AK, Bolay H, Moskowitz MA, Boas DA (2001) Dynamic imaging of cerebral blood flow using laser speckle. J Cereb Blood Flow Metab 21:195201. CrossRef Medline

Feng G, Mellor RH, Bernstein M, Keller-Peck C, Nguyen QT, Wallace M, Nerbonne JM, Lichtman JW, Sanes JR (2000) Imaging neuronal subsets in transgenic mice expressing multiple spectral variants of GFP. Neuron 28:41-51. CrossRef Medline

Fiala JC (2005) Reconstruct: a free editor for serial section microscopy. J Microsc 218:52-61. CrossRef Medline

Garcia JH, Lossinsky AS, Kauffman FC, Conger KA (1978) Neuronal ischemic injury: light microscopy, ultrastructure and biochemistry. Acta Neuropathol 43:85-95. CrossRef Medline

Greenwood SM, Mizielinska SM, Frenguelli BG, Harvey J, Connolly CN (2007) Mitochondrial dysfunction and dendritic beading during neuronal toxicity. J Biol Chem 282:26235-26244. CrossRef Medline

Halestrap AP (2006) Calcium, mitochondria and reperfusion injury: a pore way to die. Biochem Soc Trans 34:232-237. CrossRef Medline

Hartings JA, Shuttleworth CW, Kirov SA, Ayata C, Hinzman JM, Foreman B, Andrew RD, Boutelle MG, Brennan KC, Carlson AP, Dahlem MA, Drenckhahn C, Dohmen C, Fabricius M, Farkas E, Feuerstein D, Graf R, Helbok R, Lauritzen M, Major S, et al. (2016) The continuum of spreading depolarizations in acute cortical lesion development: examining Leão's legacy. J Cereb Blood Flow Metab. Advance online publication. Retrieved Jun. 21, 2016. doi: 10.1177/0271678X16654495. CrossRef Medline

Holtmaat A, Bonhoeffer T, Chow DK, Chuckowree J, De Paola V, Hofer SB, Hübener M, Keck T, Knott G, Lee WC, Mostany R, Mrsic-Flogel TD, Nedivi E, Portera-Cailliau C, Svoboda K, Trachtenberg JT, Wilbrecht L (2009) Long-term, high-resolution imaging in the mouse neocortex through a chronic cranial window. Nat Protoc 4:1128-1144. CrossRef Medline

Hori N, Carpenter DO (1994) Functional and morphological changes induced by transient in vivo ischemia. Exp Neurol 129:279-289. CrossRef Medline

Hossmann KA (2006) Pathophysiology and therapy of experimental stroke. Cell Mol Neurobiol 26:1057-1083. CrossRef Medline

Ishihara N, Jofuku A, Eura Y, Mihara K (2003) Regulation of mitochondrial morphology by membrane potential, and DRP1-dependent division and FZO1-dependent fusion reaction in mammalian cells. Biochem Biophys Res Commun 301:891-898. CrossRef Medline

Kasischke KA, Lambert EM, Panepento B, Sun A, Gelbard HA, Burgess RW, Foster TH, Nedergaard M (2011) Two-photon NADH imaging exposes boundaries of oxygen diffusion in cortical vascular supply regions. J Cereb Blood Flow Metab 31:68-81. CrossRef Medline

Kirov AS (2014) Pathological potential of neuroglia: possible new targets for medical intervention (Parpura V, Verkhratsky A, eds), pp 127-153. New York: Springer.

Kirov SA, Sorra KE, Harris KM (1999) Slices have more synapses than perfusion-fixed hippocampus from both young and mature rats. J Neurosci 19:2876-2886. Medline

Kirov SA, Petrak LJ, Fiala JC, Harris KM (2004) Dendritic spines disappear with chilling but proliferate excessively upon rewarming of mature hippocampus. Neuroscience 127:69-80. CrossRef Medline

Kleinfeld D, Mitra PP, Helmchen F, Denk W (1998) Fluctuations and stimulus-induced changes in blood flow observed in individual capillaries in layers 2 through 4 of rat neocortex. Proc Natl Acad Sci U S A 95:1574115746. CrossRef Medline

Knott AB, Perkins G, Schwarzenbacher R, Bossy-Wetzel E (2008) Mitochondrial fragmentation in neurodegeneration. Nat Rev Neurosci 9:505518. CrossRef Medline

Kremneva E, Kislin M, Kang X, Khiroug L (2013) Motility of astrocytic mitochondria is arrested by $\mathrm{Ca}^{2+}$-dependent interaction between mitochondria and actin filaments. Cell Calcium 53:85-93. CrossRef Medline

Kunz A, Dirnagl U, Mergenthaler P (2010) Acute pathophysiological processes after ischaemic and traumatic brain injury. Best Pract Res Clin Anaesthesiol 24:495-509. CrossRef Medline

Labat-gest V, Tomasi S (2013) Photothrombotic ischemia: a minimally invasive and reproducible photochemical cortical lesion model for mouse stroke studies. J Vis Exp 2013:76. CrossRef Medline

Lee JM, Zipfel GJ, Choi DW (1999) The changing landscape of ischaemic brain injury mechanisms. Nature 399:A7-A14. CrossRef Medline

Li Z, Okamoto K, Hayashi Y, Sheng M (2004) The importance of dendritic mitochondria in the morphogenesis and plasticity of spines and synapses. Cell 119:873-887. CrossRef Medline

Lihavainen E, Mäkelä J, Spelbrink JN, Ribeiro AS (2012) Mytoe: automatic analysis of mitochondrial dynamics. Bioinformatics 7:10501051. CrossRef Medline

Lihavainen E, Kislin M, Toptunov D, Khiroug L, Ribeiro AS (2015) Automatic quantification of mitochondrial fragmentation from two-photon microscope images of mouse brain tissue. J Microsc 260:338-351. CrossRef Medline

Liot G, Bossy B, Lubitz S, Kushnareva Y, Sejbuk N, Bossy-Wetzel E (2009) Complex II inhibition by 3 -NP causes mitochondrial fragmentation and neuronal cell death via an NMDA- and ROS-dependent pathway. Cell Death Differ 16:899-909. CrossRef Medline

Liu RR, Murphy TH (2009) Reversible cyclosporin A-sensitive mitochondrial depolarization occurs within minutes of stroke onset in mouse somatosensory cortex in vivo: a two-photon imaging study. J Biol Chem 284:36109-36117. CrossRef Medline

Liu W, Tian F, Kurata T, Morimoto N, Abe K (2012) Dynamic changes of mitochondrial fusion and fission proteins after transient cerebral ischemia in mice. J Neurosci Res 1189:1183-1189. CrossRef Medline

Matsumoto S, Friberg H, Ferrand-Drake M, Wieloch T (1999) Blockade of the mitochondrial permeability transition pore diminishes infarct size in the rat after transient middle cerebral artery occlusion. J Cereb Blood Flow Metab 19:736-741. CrossRef Medline

Mattson MP, Gleichmann M, Cheng A (2008) Mitochondria in neuroplasticity and neurological disorders. Neuron 60:748-766. CrossRef Medline

Meeusen S, McCaffery JM, Nunnari J (2004) Mitochondrial fusion intermediates revealed in vitro. Science 305:1747-1752. CrossRef Medline

Misgeld T, Kerschensteiner M, Bareyre FM, Burgess RW, Lichtman JW (2007) Imaging axonal transport of mitochondria in vivo. Nat Methods 4:559-561. CrossRef Medline

Mouli PK, Twig G, Shirihai OS (2009) Frequency and selectivity of mitochondrial fusion are key to its quality maintenance function. Biophys J 96:3509-3518. CrossRef Medline

Murphy TH, Li P, Betts K, Liu R (2008) Two-photon imaging of stroke onset in vivo reveals that NMDA-receptor independent ischemic depolarization is the major cause of rapid reversible damage to dendrites and Spines. J Neurosci 28:1756-1772. CrossRef Medline

Otera H, Ishihara N, Mihara K (2013) New insights into the function and regulation of mitochondrial fission. Biochim Biophys Acta 1833:12561268. CrossRef Medline

Owens K, Park JH, Gourley S, Jones H, Kristian T (2015) Mitochondrial dynamics: cell-type and hippocampal region specific changes following global cerebral ischemia. J Bioenerg Biomembr 47:13-31. CrossRef Medline

Parone PA, Da Cruz S, Tondera D, Mattenberger Y, James DI, Maechler P, Barja F, Martinou JC (2008) Preventing mitochondrial fission impairs mitochondrial function and leads to loss of mitochondrial DNA. PLoS One 3:e3257. CrossRef Medline

Paveliev M, Kislin M, Molotkov D, Yuryev M, Rauvala H, Khiroug L (2014) Acute brain trauma in mice followed by longitudinal two-photon imaging. J Vis Exp 2014:86. CrossRef Medline

Peng J, Lin C, Chen Y, Kao L (2011) Automatic morphological subtyping reveals new roles of caspases in mitochondrial dynamics. PLoS Comput 7:e1002212. CrossRef Medline 
Peron S, Chen TW, Svoboda K (2015) Comprehensive imaging of cortical networks. Curr Opin Neurobiol 32:115-123. CrossRef Medline

Pivovarova NB, Nguyen HV, Winters CA, Brantner CA, Smith CL, Andrews SB (2004) Excitotoxic calcium overload in a subpopulation of mitochondria triggers delayed death in hippocampal neurons. J Neurosci 24: 5611-5622. CrossRef Medline

Popov V, Medvedev NI, Davies HA, Stewart MG (2005) Mitochondria form a filamentous reticular network in hippocampal dendrites but are present as discrete bodies in axons: a three-dimensional ultrastructural study. J Comp Neurol 492:50-65. CrossRef Medline

Rintoul GL, Filiano AJ, Brocard JB, Kress GJ, Reynolds IJ (2003) Glutamate decreases mitochondrial size and movement in primary forebrain neurons. J Neurosci 23:7881-7888. Medline

Risher WC, Ard D, Yuan J, Kirov SA (2010) Recurrent spontaneous spreading depolarizations facilitate acute dendritic injury in the ischemic penumbra. J Neurosci 30:9859-9868. CrossRef Medline

Risher WC, Croom D, Kirov SA (2012) Persistent astroglial swelling accompanies rapid reversible dendritic injury during stroke-induced spreading depolarizations. Glia 60:1709-1720. CrossRef Medline

Rodriguez A, Ehlenberger DB, Dickstein DL, Hof PR, Wearne SL (2008) Automated three-dimensional detection and shape classification of dendritic spines from fluorescence microscopy images. PLoS One 3:e1997. CrossRef Medline

Rugarli EI, Langer T (2012) Mitochondrial quality control: a matter of life and death for neurons. EMBO J 31:1336-1349. CrossRef Medline

Schinzel AC, Takeuchi O, Huang Z, Fisher JK, Zhou Z, Rubens J, Hetz C, Danial NN, Moskowitz MA, Korsmeyer SJ (2005) Cyclophilin D is a component of mitochondrial permeability transition and mediates neuronal cell death after focal cerebral ischemia. Proc Natl Acad Sci U S A 102:12005-12010. CrossRef Medline

Shitara H, Kaneda H, Sato A, Iwasaki K, Hayashi J, Taya C, Yonekawa H (2001) Non-invasive visualization of sperm mitochondria behavior in transgenic mice with introduced green fluorescent protein (GFP). FEBS Lett 500:7-11. CrossRef Medline

Sigler A, Goroshkov A, Murphy TH (2008) Hardware and methodology for targeting single brain arterioles for photothrombotic stroke on an upright microscope. J Neurosci Methods 170:35-44. CrossRef Medline

Solenski NJ, diPierro CG, Trimmer PA, Kwan AL, Helms GA (2002) Ultrastructural changes of neuronal mitochondria after transient and permanent cerebral ischemia. Stroke 33:816-824. CrossRef Medline

Steffensen AB, Sword J, Croom D, Kirov SA, MacAulay N (2015) Chloride cotransporters as a molecular mechanism underlying spreading depolarization-induced dendritic beading. J Neurosci 35:12172-12187. CrossRef Medline
Svoboda K, Denk W, Kleinfeld D, Tank DW (1997) In vivo dendritic calcium dynamics in neocortical pyramidal neurons. Nature 385:161-165. CrossRef Medline

Sword J, Masuda T, Croom D, Kirov SA (2013) Evolution of neuronal and astroglial disruption in the peri-contusional cortex of mice revealed by in vivo two-photon imaging. Brain 136:1446-1461. CrossRef Medline

Sword J, Croom D, Wang PL, Thompson RJ, Kirov SA (2016) Neuronal pannexin-1 channels are not molecular routes of water influx during spreading depolarization-induced dendritic beading. J Cereb Blood Flow Metab. Advance online publication. Retrieved Mar. 18, 2016. doi: 10.1177/0271678X16639328. CrossRef Medline

Tomimoto H, Yanagihara T (1992) Electron microscopic investigation of the cerebral cortex after cerebral ischemia and reperfusion in the gerbil. Brain Res 598:87-97. CrossRef Medline

Tomimoto H, Yanagihara T (1994) Golgi electron microscopic study of the cerebral cortex after transient cerebral ischemia and reperfusion in the gerbil. Neuroscience 63:957-967. CrossRef Medline

Twig G, Elorza A, Molina AJ, Mohamed H, Wikstrom JD, Walzer G, Stiles L, Haigh SE, Katz S, Las G, Alroy J, Wu M, Py BF, Yuan J, Deeney JT, Corkey BE, Shirihai OS (2008) Fission and selective fusion govern mitochondrial segregation and elimination by autophagy. EMBO J 27:433-446. CrossRef Medline

Wappler EA, Institoris A, Dutta S, Katakam PV, Busija DW (2013) Mitochondrial dynamics associated with oxygen-glucose deprivation in rat primary neuronal cultures. PLoS One 8:e63206. CrossRef Medline

Watson BD, Dietrich WD, Busto R, Wachtel MS, Ginsberg MD (1985) Induction of reproducible brain infarction by photochemically initiated thrombosis. Ann Neurol 17:497-504. CrossRef Medline

Yang O, Cuccia D, Choi B (2011) Real-time blood flow visualization using the graphics processing unit. J Biomed Opt 16:016009. CrossRef Medline

Yin W, Signore AP, Iwai M, Cao G, Gao Y, Chen J (2008) Rapidly increased neuronal mitochondrial biogenesis after hypoxic-ischemic brain injury. Stroke 39:3057-3063. CrossRef Medline

Youle RJ, Karbowski M (2005) Mitochondrial fission in apoptosis. Nat Rev Mol Cell Biol 6:657-663. CrossRef Medline

Zhang S, Murphy TH (2007) Imaging the impact of cortical microcirculation on synaptic structure and sensory-evoked hemodynamic responses in vivo. PLoS Biol 5:1152-1167. CrossRef Medline

Zhang S, Boyd J, Delaney K, Murphy TH (2005) Rapid reversible changes in dendritic spine structure in vivo gated by the degree of ischemia. J Neurosci 25:5333-5338. CrossRef Medline 